\title{
Lexicografia das línguas de sinais: resgate histórico e estudo descritivo
}

\section{Sign language Lexicography: historical rescue and descriptive study}

\section{Lexicografía del lenguaje de señales: rescate histórico y estudio descriptivo}

\author{
(iD) Érika Lourrane Leôncio \\ Instituto Federal de Educação, Ciência e Tecnologia (IFPI), Tereseina, Piauí, Brasil. \\ E-mail: erika.lourrane@ifpi.edu.br \\ (iD) Claudia Zavaglia \\ Universidade Estadual Paulista Júlio de Mesquita Filho (UNESP), São José do Rio Preto, \\ São Paulo, Brasil. \\ E-mail: claudia.zavaglia@unesp.br
}

\begin{abstract}
Resumo: Este artigo apresenta um resgate histórico das produções lexicográficas das Línguas de Sinais no mundo e, mais detidamente, no Brasil. As discussões foram amparadas em Krieger (2006), Sofiato e Reily (2012), Felipe (2000), principalmente. A análise das fontes históricas ocorreu, parcialmente, no Instituto Nacional de Educação de Surdos (INES). Numa dimensão diacrônica, a pesquisa partiu da Idade Média até o século XXI, retomando a raiz da Lexicografia das Língua de Sinais e a identificação da origem do registro da Libras, bem como as motivações e interesses que mobilizaram a produção de simples listas, manuais e glossários a legítimos dicionários.
\end{abstract}

Palavras-chave: Libras. Lexicografia. História

\begin{abstract}
This article presents a historical rescue of the lexicographic productions of Sign Language - SL in the world and, more closely, in Brazil. The discussions were based on Krieger (2006), Sofiato and Reily (2012), Felipe (2000), mainly. The analysis of historical sources occurred,
\end{abstract}


partially, at the National Institute of Deaf Education (NIDE). In a diachronic dimension, the research started from the Middle Ages until the 21st century, taking up the roots of the SL's Lexicography and enabling the identification of the origin of Libras register, as well as the motivations and interests that mobilized the production of simple lists, handbooks and glossaries to legitimate dictionaries.

Keywords: Libras. Lexicography. History

Resumen: Este artículo presenta un rescate histórico de las producciones lexicográficas dela Lengua de señas-LS en el mundoy, más específicamente en Brasil. Las discusiones, primordialmente, fueron apoyadas en Krieger (2006), Sofiato y Reily (2012), Felipe (2000). El análisis de las fuentes históricas se produjo, en parte, en el Instituto Nacional de Educación para Sordos (INES). En una dimensión diacrónica, la investigación parte de la Edad Media hasta el siglo XXI, retomando las raíces de la lexicografía de las LS y permitiendo la identificación del origen del registro de Libras, así como las motivaciones e intereses que movilizaron la producción de listas sencillas, manuales y glosarios hasta diccionarios más completos.

Palabras clave: Libras. Lexicografía. Historia

Submetido em 24 de abril de 2020.

Aceito em 25 de agosto de 2020.

Publicado em 08 de julho de 2021. 


\section{Introdução}

Este artigo, de cunho Metalexicografico, é resultado de parte da pesquisa de Mestrado, intitulada Proposta lexicográfica para verbetes de dicionário especial de homônimos da Língua Brasileira de Sinais - Libras, desenvolvida no Programa de Pós-Graduação em Letras da Universidade Federal do Piauí - UFPI, por Érika Laurrane Leôncio, em 2019.

Neste trabalho, foi desenvolvido o levantamento histórico dos registros lexicográficos de países que foram berço da Lexicografia da língua de sinais (abreviada por LS) e que influenciaram o desenvolvimento da Ciência também em outros países. A intenção desta pesquisa foi, sobretudo, conhecer as tipologias lexicográficas que iniciaram a prática de dicionarização da língua no Brasil como também conhecer o continuum de produções, a arquitetura e escolhas lexicográficas empregadas na macro e microestrutura de manuais vocabular, listas de vocabulários e dicionários de Libras.

A pesquisa bibliográfica, e do tipo documental, foi empregada para o recolhimento e análise de obras lexicográficas da Idade Média (no mundo) e do Período Imperial até a primeira década do século XXI, no Brasil. O corpus de análise foi oriundo do acervo próprio das pesquisadoras e das bibliotecas histórica e setorial do Instituto Nacional de Educação de Surdos (INES).

O registro histórico da Lexicografia das LS, no mundo, foi amparado nos estudos de Sofiato (2005), Sofiato e Realy (2012), Eriksson (1993), Costa e Nascimento (2015), principalmente, e o corpus de análise das obras brasileiras foi composto por 04 manuais, 02 listas de vocabulários e 06 dicionários, listados a seguir: 
Lexicografia das línguas de sinais: resgate histórico e estudo descritivo Érika Lourrane Leôncio • Claudia Zavaglia

\section{Quadro1 - Corpus da Pesquisa}

\begin{tabular}{|c|c|}
\hline MANUAIS & $\begin{array}{l}\text { 1. Iconografia dos Signaes dos Surdos-Mudos (GAMA, 1875) } \\
\text { 2. Linguagem de Sinais do Brasil (HOEMANN; OATES; HOEMANN, } \\
\text { 1963); } \\
\text { 3. Linguagem das Mãos (OATES, 1969) } \\
\text { 4. Libras: a imagem do pensamento (KOJIMA; SEGALA, 2012) }\end{array}$ \\
\hline VOCABULÁRIOS & $\begin{array}{l}\text { 1. Linguagem de Sinais: As mãos também falam (INES, [1856]). } \\
\text { 2. Glossário Comunicando com as Mãos (ALBUQUERQUE, [1856]) }\end{array}$ \\
\hline DICIONÁRIOS & $\begin{array}{l}\text { 1. Dicionário Enciclopédico Ilustrado Trilíngue: Língua Brasileira de } \\
\text { Sinais - LIBRAS (CAPOVILLA; RAPHAEL, 2001) } \\
\text { 2. Dicionário Enciclopédico Ilustrado Trilíngue: Língua de Sinais Brasi- } \\
\text { leira (CAPOVILLA; RAPHAEL, 2006) } \\
\text { 3. Dicionário enciclopédico ilustrado trilíngue da Língua de Sinais Bra- } \\
\text { sileira (Libras) (CAPOVILLA; RAPHAEL; Maurício, 2012) } \\
\text { 4. Dicionário da Língua de Sinais do Brasil: a Libras em suas mãos } \\
\text { (CAPOVILLA et al., 2017) } \\
\text { 5. Dicionário Virtual da Língua Brasileira de Sinais - LIBRAS (DV-Libras, } \\
\text { 2005) } \\
\text { 6. DV-LIBRAS VERSÕES 2.1(2008) e a } 3.0 \text { (2011) }\end{array}$ \\
\hline
\end{tabular}

Fonte: Própria da Pesquisa (2020)

\section{Lexicografia das línguas de sinais no mundo}

Conforme Sofiato e Reily (2012), a história das LS está intimamente relacionada à história da igreja cristã e ao voto de silêncio eclesiástico. Sobre isso, Harry Hoemann (HOEMANN, OATES, HOEMANN, 1983, p. 51) informou, no prefácio do Manual Linguagem de Sinais do Brasil (terceira obra lexicográfica brasileira), que "motivos religiosos despertaram grande parte da atenção que as pessoas surdas receberam" na época que o material foi produzido.

Apesar dos sinais caseiros ou combinados já fazerem parte do cotidiano do surdo e de religiosos, "a sistematização e o registro gráfico e descritivo dos sinais surgiu pela primeira vez na história da humanidade no contexto da constituição da vida monástica na Idade Média" (SOFIATO; REILY, 2012, p. 12). Os fins foram de várias ordens, quais sejam: religiosos (acompanhar a liturgia, tradução de textos bíblicos, hinos, outros); econômicos, jurídicos (doações, 
Lexicografia das línguas de sinais: resgate histórico e estudo descritivo Érika Lourrane Leôncio • Claudia Zavaglia

testamentos, documentos de contabilidade da igreja) e educacionais (ensino dos noviços visando às missões).

Conforme Sofiato e Reily (2012), os primeiros registros escritos dessa língua foram encontrados na Europa e na América do Norte, nos mosteiros de Cluny, no Monasteriale, e em outro mosteiro do sudoeste da Alemanha, cujo nome do local não foi informado pelas autoras (SOFIATO; REILY, 2012). A lista do Monasteriale é considerada a listagem mais antiga do inglês arcaico, que chegou a ser traduzida para o latim e foi uma das cinco listas encontradas no local. Sofiato (2005) concluiu, em suas pesquisas, que esse documento se tratava de um registro instrucional, supostamente, composto por 127 sinais (alguns com ilustração) prescritos verbalmente e agrupados por campos semânticos e tecnoletos (atividades, missa, objetos e literatura religiosa).

O volume do livro De Computo Vel Loquela Digitorum, escrito por Bede (672-735), foi também considerado o primeiro registro monástico da eclesia inglesa (Sofiato; Reily, 2012 apud Eriksson, 1993). Em seguida, outros materiais surgiram para registrar 'elementos específicos' dos sinais, como o Thesaurus Artificiosae Memorariae, publicado, postumamente, em 1679 (continha cinco pranchas ilustradas com três variações dos alfabetos unimanuais), o trabalho de Giovanni Battista della Porta, por sua vez, intitulado De Furtivis Literarum Notis, publicado em 1563, o qual propunha associar letras e partes do corpo com dêixis (SOFIATO; REILY, 2012), e o Refugium Informorum, obra póstuma ilustrada pelo Padre Melchior de Yebra (ERIKSSON, 1993), que ilustrou, dentre outros, as posições do alfabeto manual da Alemanha.

Apesar dos registros e informações sobre os sinais, nenhum desses manuscritos eram propriamente dicionários, já que suas características e informações estavam mais próximas a manuais, vocabulários ou glossários. Para Sofiato (2005), a obra que mais se aproximou a um modelo de dicionário foi o Monasteriales Indicia, que data do período da Idade Média. Logo, apesar de a igreja ter feito os primeiros ensaios para a produção de dicionários, foi a 
Lexicografia das línguas de sinais: resgate histórico e estudo descritivo Érika Lourrane Leôncio • Claudia Zavaglia

educação a verdadeira grande impulsionadora da cultura de elaboração desses materiais.

Disso, sublinhamos que foi Pedro Ponce de Leon (1520-1584), monge beneditino do Monastério de Oña, o primeiro grande educador de surdos a inaugurar essa nova fase do trabalho de registro e documentação das línguas de sinais. Ele aprendeu a se comunicar por sinais em razão do voto de silêncio, muito comum entre os monges (SCHLÜNZEN; DI BENEDETTO; SANTOS, 2013), e foi o primeiro a se manifestar a favor da escolarização do surdo. O Monastério Valladolid, onde Ponce de Leon trabalhava, foi o primeiro a oferecer educação aos filhos da nobreza. O agrupamento dos surdos nesse lugar foi determinante para que os gestos criados nas famílias e nos monastérios adquirissem legitimação entre os surdos e passassem de um sistema de comunicação por gestos para uma língua legítima.

Com isso, as primeiras manifestações e registros destinados ao ensino do surdo foram as do próprio Ponce de Leon, as de Juan Pablo Bonet e, posteriormente, as de Charles Michel de L`Épée, para citar os mais importantes. Bonet apropriou-se do método de trabalho e do alfabeto manual de Ponce de Leon e publicou o manual intitulado Redução das letras e a arte de ensinar os mudos a falar (em espanhol, Reduccíon de las letras y arte para enseñar hablar a los mudos), primeiro livro da educação de surdos, publicado em 1620 (INES, 2008). L'Épée fundador da primeira escola para o ensino de surdos, também teve uma obra atribuída ao seu nome, o livro A verdadeira maneira de instruir os surdos-mudos (1784). No compêndio, havia registros sobre as regras sintáticas e o alfabeto manual idealizado por Ponce de Leon. Sicard, Valade e Bébian foram, segundo Sofiato e Reily (2012), alguns idealizadores de dicionário da LS. Porém, destes, o trabalho mais próximo a um dicionário foi o de Valade, porque, segundo as autoras, esse material "consistia num dicionário de sinais manuais, que trazia uma lista de palavras-chave em francês, cada uma, seguida de uma descrição verbal dos sinais gestuais naturais correspondentes" (SOFIATO; REILY, 2012, p. 15). Além desses, outros cinco títulos foram 
Lexicografia das línguas de sinais: resgate histórico e estudo descritivo Érika Lourrane Leôncio • Claudia Zavaglia

listados por Costa e Nascimento (2015) numa ordem cronológica. As autoras apontaram que:

O primeiro dicionário de língua de sinais foi publicado na França em 1776 pelo abade Charles-Michael de L`Épée intitulado "L 'institution de sourts muets, por la voice des signes methodiques". Além deste, em 1808, o gramático Roch-Ambroide Cucurron Sicard, sucessor do L'Épée, publicou "De la thèorie des signes", em 1825, "Mimographie" de Roch-Ambroise Auguste Bébian, em 1854, "Etudes sur la lexicologie et al grammaire du langage naturel des signes" por Y. L. R. Valade, em 1856, “L 'enseignement primaire du langage naturel mis à la portée de tout Le monde avec une icnographie des signes" de P. Pélissier e em 1897, "Dictionnaire des sourds-muets" de J. Ferrand. Nos Estados Unidos, em 1965, W. C. Stokoe, D. Casterline e C. G. Croneberg publicaram "A dictionary of American Sing Language on Linguistic Principles" (CAPOVILLA, RAPHAEL, MAURÍCIO, 2009 apud COSTA; NASCIMENTO, 2015, p. 148).

Desse universo de obras, Faria-do-Nascimento (2009) concluiu que o considerado dicionário de Roch-Ambrois e Bébian, retomado por Valade em 1850, foi o mais completo. Ele possuía a indicação de caracteres ilustrativos do formato da mão e do movimento com setas, além de símbolos indicativos do tipo, direção, velocidade e frequência do movimento do tronco, perna, pé e das posições gestuais das mãos, braços e face (Figura 01), como não havia nos demais. 
Lexicografia das línguas de sinais: resgate histórico e estudo descritivo

Figura 1 - Mimographie, de Bébian
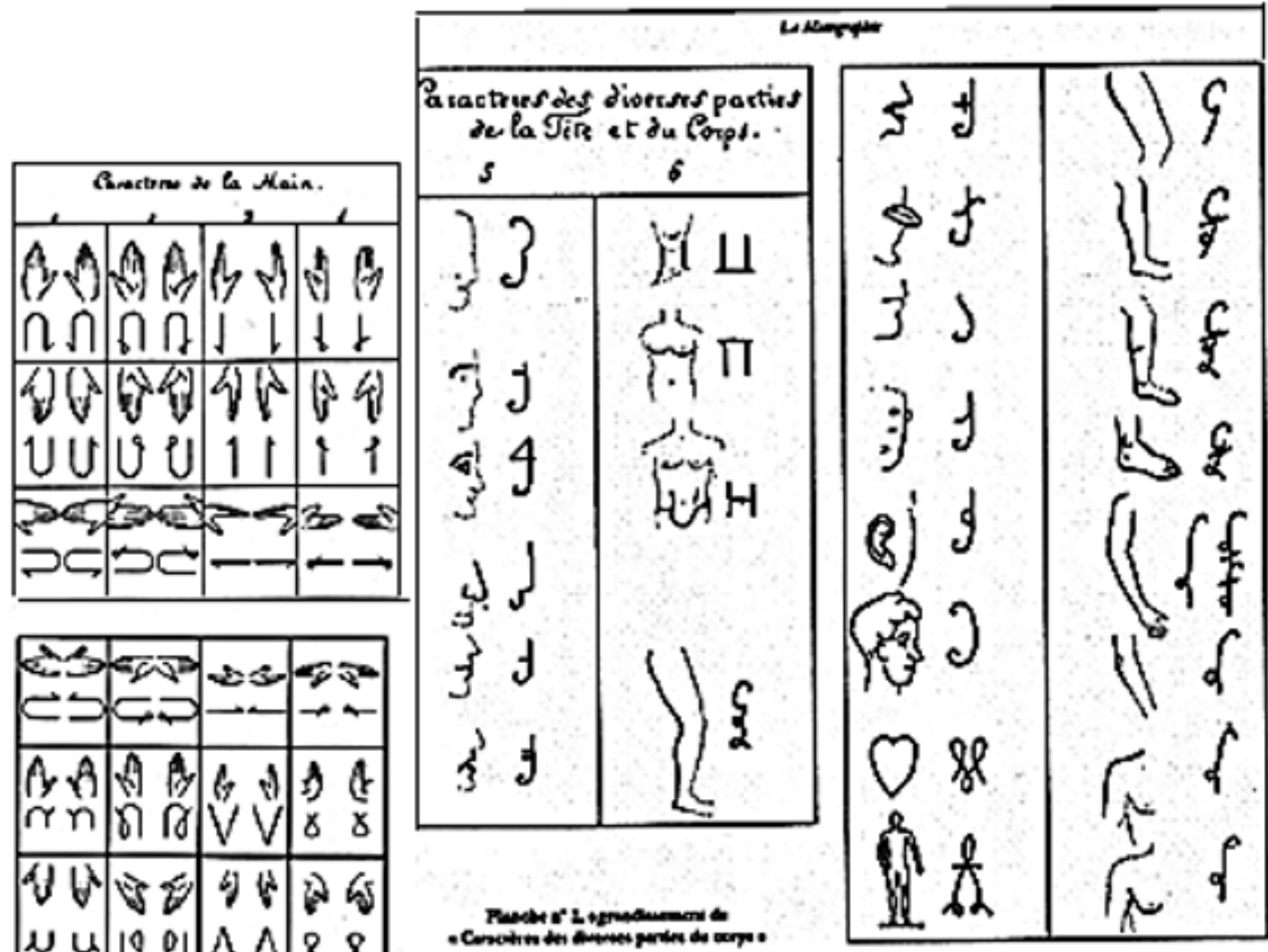

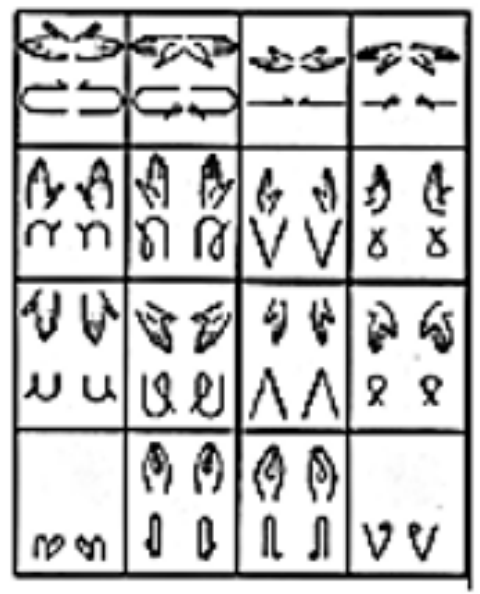

Fonte: Sofiato (2005, p. 21-22).

Ao contrário do que, até certo período, foi sistematicamente difundido na literatura, foi Bébian quem primeiro identificou e decompôs os sinais em unidades mínimas sem significado (Configuração de Mão - CM, Locação - L ou Ponto de Locação - PA, Movimento - M, Expressão Facial - EF e Orientação da Palma da Mão - OR), basta, para isso, verificar, nas páginas do Minographie, a descrição e a ilustração de tais parâmetros. Os caracteres mimográficos organizados na Figura 1 são uma mostra da decomposição dos sinais chamados "gestos elementares". ${ }^{1}$ A inclusão da ilustração

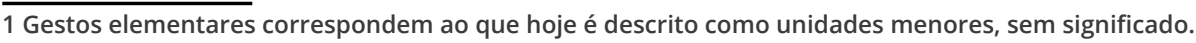


Lexicografia das línguas de sinais: resgate histórico e estudo descritivo Érika Lourrane Leôncio • Claudia Zavaglia

do formato da mão, o uso de setas e símbolos indicativos do tipo, direção, velocidade e frequência do $M$, além de tipos de manifestações da face (EF) e outros, representaram um grande avanço para obras lexicográficas da época. Isto porque as reflexões linguísticas na área da Fonética e Fonologia da LS iniciaram de fato com Bébian, antes mesmo que Stokoe (1960) divulgasse os resultados de suas futuras pesquisas, em que apresentou três (CM, PA e M) dos cinco parâmetros, antes compartilhados por Bébian (OVÍDEO, 2009; FELIPE, 2014).

A seminal descoberta de Bébian, no século XIX, forneceu à sua obra um status mais normativo e prescritivo, comparada às demais produzidas na sua época e até mesmo após. Apesar desse passo, a Lexicografia da LS passou por um longo período de ócio em virtude da proibição do uso e disseminação da língua. Essa proibição, resultado da decisão, no /l Congresso Internacional de Educação de Surdos-Mudos ou Congresso de Milão (1880)², como ficou conhecido, estabeleceu em ata, na seção sobre os "Métodos da Educação", que:

Considerando a incontestável superioridade da linguagem oral sobre a de sinais na reintegração do surdo-mudo à sociedade, permitindo a mais perfeita aquisição do conhecimento, Declara: Que se deve dar preferência ao Método Oral ao invés do método de sinais para a educação e ensino do surdo-mudo (GAMA, 2011 [1875], p. 4).

Consequentemente, em virtude da erradicação da LS das escolas, no período que compreende o século XIX até meados do século XX, na Europa e na América (SOFIATO, 2005), a história da Lexicográfica da LS foi dividida em dois grandes períodos, quais sejam: Pré-Congresso de Milão (até 1880) e Pós-Era Congresso de Milão (a partir de 1960, com o início das pesquisas linguísticas de Stokoe). Moura (2000) relembra que, com a aprovação das resolu-

2 Congresso a favor da normatização do surdo por meio da oralização. Proibiu o uso da língua de sinais dentro e fora das instituições educacionais (MOURA, 2000). 
Lexicografia das línguas de sinais: resgate histórico e estudo descritivo Érika Lourrane Leôncio • Claudia Zavaglia

ções estabelecidas no Congresso de Milão, a educação ficou totalmente sob o domínio da filosofia oralista, as produções na área da LS cessaram e, somente após essa fase, novas obras começaram a ser produzidas e publicadas livremente. O manual de Pélissier (1856), reproduzido por Flausino da Gama (SOFIATO, 2005), esteve dentre as obras publicadas em todo o mundo até a legitimação das decisões do Congresso de Milão.

A história formal da Lexicografia no Brasil teve início em 1875 com a publicação da obra de Gama (apesar do material ser uma espécie de tradução do material de Pélissier), no período Pré-Congresso de Milão, conforme ressaltou Felipe (2000, p. 87), “aqui no Brasil, a primeira publicação sobre a língua brasileira de sinais data de 1875, trata-se de um livro com características de manual, o Iconografia dos Signaes dos Surdos-Mudos, de Flausino da Gama". Essa e as principais obras de registro da Libras, publicadas do século XIX aos dias atuais, serão apresentadas e discutidas na seção a seguir.

\section{Lexicografia da língua de sinais no Brasil}

O século XIX configura-se como um marco histórico para a Lexicografia da Libras, sobretudo, porque foi nesse período que surgiu a primeira referência lexicográfica da língua, a obra intitulada Iconographia dos Signaes dos Surdos-Mudos, de Flausino Gama. Sob forte influência francesa, o atual INES, antes denominado Instituto Imperial de Surdos-Mudos, favoreceu a publicação desse trabalho, em $1875^{3}$. A impressão litográfica do Iconographia dos Signaes dos Surdos- Mudo teve, para Tobias Leite (então diretor), dois fins, descritos a seguir:

$1^{\circ}$ Vulgarizar a linguagem dos signaes, meio predileto dos sur-
dos mudos para a manifestação dos seus pensamentos. Os pais,
os professores primários, e todos os que se interessarem por

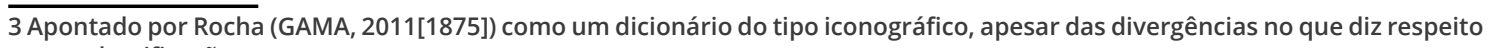
a essa classificação. 
Lexicografia das línguas de sinais: resgate histórico e estudo descritivo

Érika Lourrane Leôncio • Claudia Zavaglia

esses infelizes, ficarão habilitados para os entender e se fazerem entender. $2^{\circ}$ Mostrar o quanto deve ser apreciado um surdo-mudo educado (GAMA, 1875, p. 12).

Com base nos estudos comparativos de Sofiato (2005), o Iconographia dos Signaes dos Surdos-Mudos foi uma compilação do livro L'Enseigment Primaire des Sourds-Muets Mis à la portée de Tout le Monde avec Une Iconographie des signes de Pélissier, como dito na seção anterior. Na época, era comum a tradução, para o português, de livros franceses, utilizados no Instituto de Paris (INES, 2008). Porém, pela natureza e função dos vocabulários, glossários e dicionários (guardar o léxico de uma comunidade linguística específica), além das diferenças no sistema linguístico da língua de cada país, não faria sentido que eles também fossem traduzidos.

Sobre o assunto, Felipe $(2000,2014)$ explica que as propostas metodológicas das primeiras escolas de surdos da Espanha e da França serviram de base para outros países, e que, muito provavelmente, a Língua de Sinais Francesa - LSF foi utilizada também no INES na época de Gama, uma vez que o primeiro diretor da instituição foi um surdo francês, sendo, portanto, pertinente a tradução e incorporação de algumas modificações ao material.

Com efeito, a LSF influenciou, em grande medida, a Libras. Possivelmente, por isso, o manual vocabular ${ }^{4}$ de Pélissier foi, em grande parte, traduzido para o português. Para Sofiato (2011, p. 59, grifo do autor), "Flausino não buscou 'inspiração' no livro de Pélissier e sim copiou ipsis literis as estampas do mesmo para produzir o Iconografia dos Signaes dos Surdos-Mudos". Logo, apesar das contribuições da obra de Gama a professores e alunos (INES, 2008), a fonte não pode ser considerada legitimamente brasileira, já que o seu repertório de sinais é, predominantemente, da LSF.

O manual vocabular de Pélissier e, posteriormente, o Iconographia dos Signaes dos Surdos-Mudos foram organizados por categorias semânticas (alimentos, bebidas, objetos de mesa, dentre

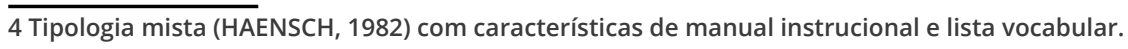


Lexicografia das línguas de sinais: resgate histórico e estudo descritivo Érika Lourrane Leôncio • Claudia Zavaglia

outras) e por classificação gramatical (adjetivos, pronomes, verbos, dentre outras). Além disso, cada sinal foi numerado com a explicação verbal na página subsequente, conforme mostrado na Figura 2, a seguir:

Figura 2 - Estampa II - alimentos objetos de mesa e instrução para execução dos sinais

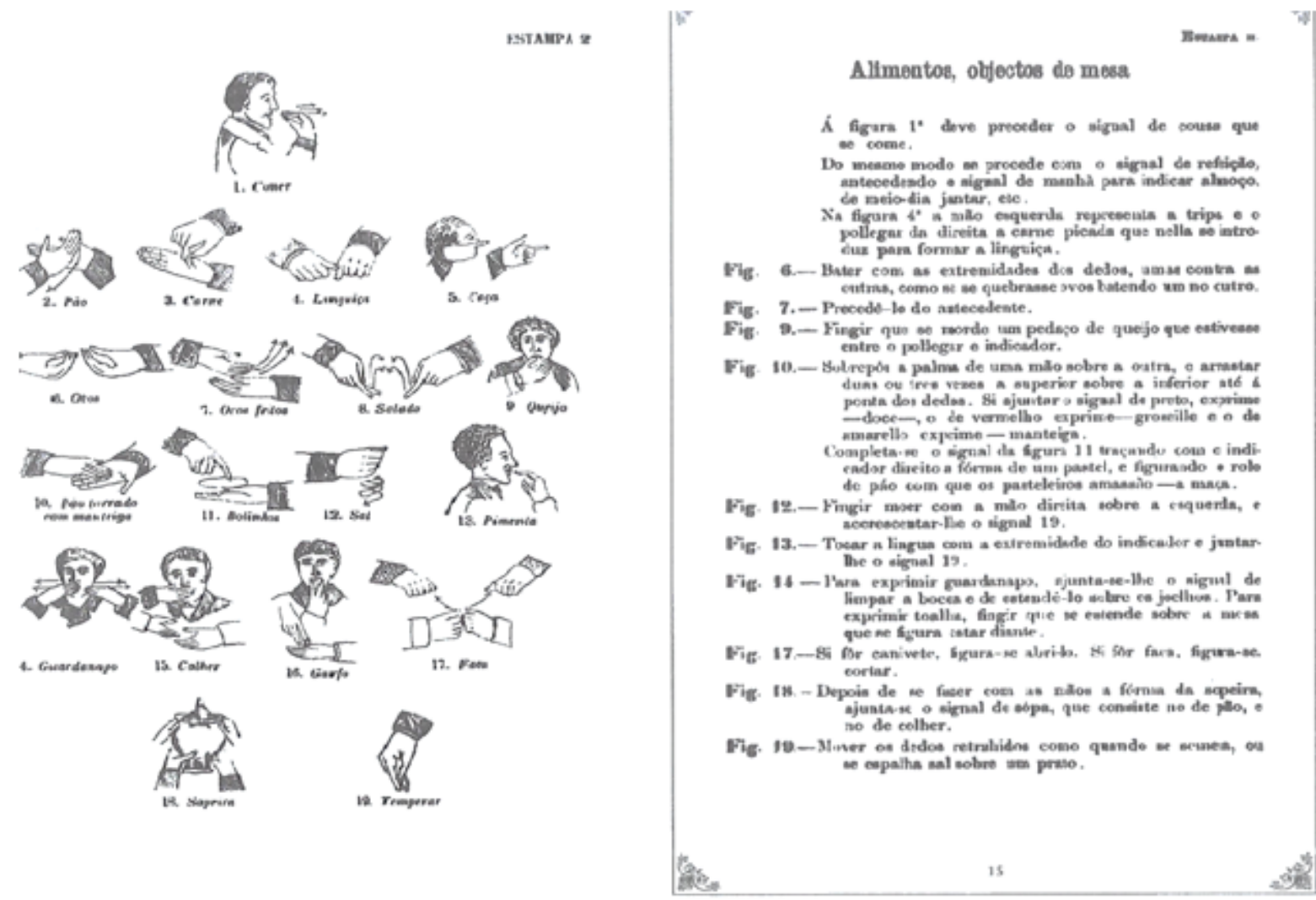

Fonte: Gama (1875, p. 14-15).

Apesar das estampas (espécie de técnica de impressão litográfica) serem idênticas (Figuras 2 e 3), o manual de Pélissier registrou o total de 302 sinais, em15 estampas; e o de Gama foi além, com 382 sinais, em 20 estampas. 
Lexicografia das línguas de sinais: resgate histórico e estudo descritivo Érika Lourrane Leôncio • Claudia Zavaglia

Figura 3 - PLANCHE II - Aliments et objets de table

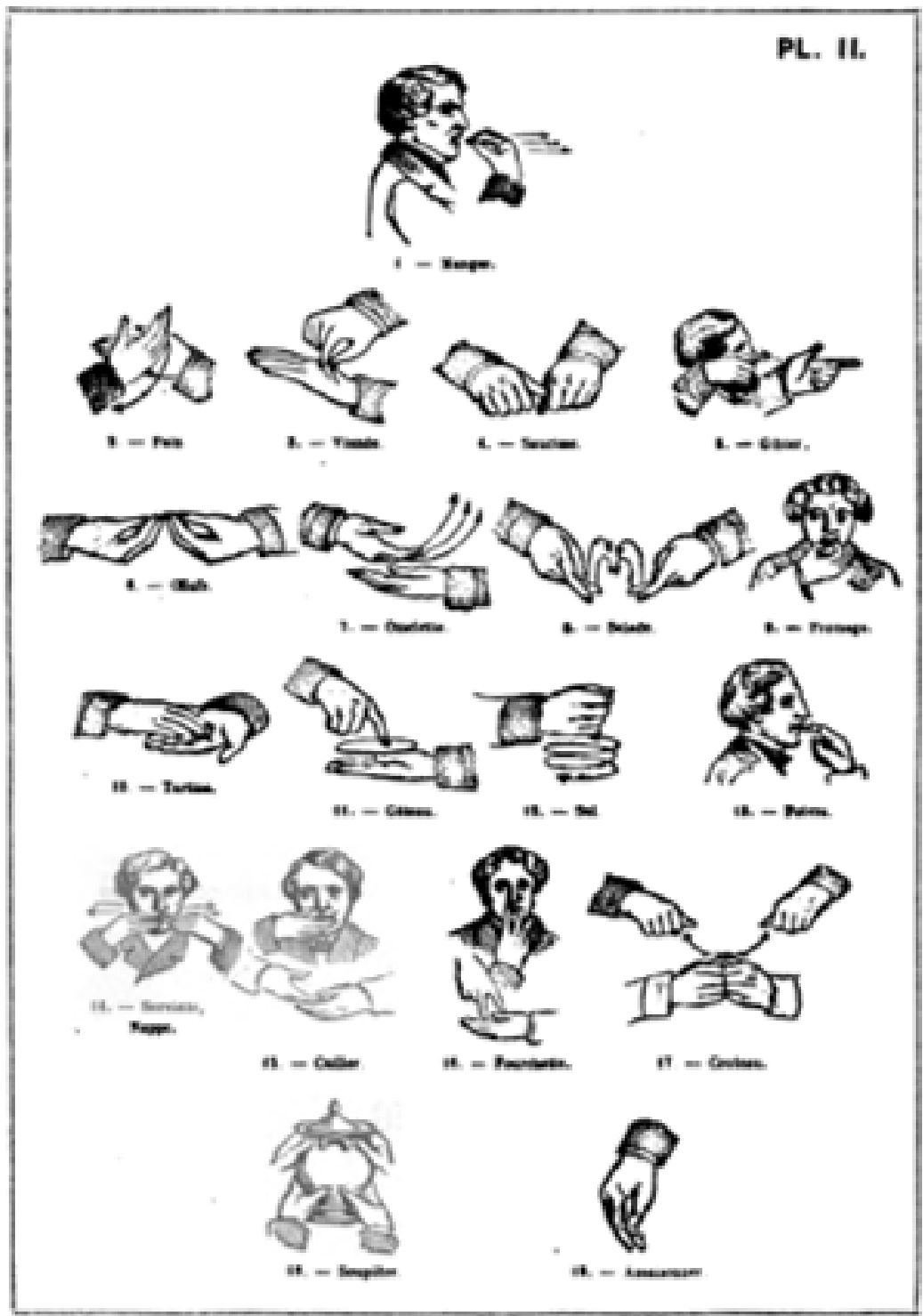

Fonte: Pélissier (1856).

O Iconografia dos Sinais dos Surdos-Mudos, mesmo, possivelmente, não registrando efetivamente o léxico corrente entre os surdos das províncias brasileiras, trouxe fortes contribuições para a educação e a Lexicografia daqui. Ele inspirou e incentivou a criação de livros de vocabulários com sinais ilustrados, como as obras Linguagem de Sinais: As mãos também falam e Comunicando com as Mãos, também produzidos no INES, além de glossários e até mesmo dicionários. 
Lexicografia das línguas de sinais: resgate histórico e estudo descritivo Érika Lourrane Leôncio • Claudia Zavaglia

Esses e outros materiais lexicográficos da biblioteca histórica do INES foram, com a colaboração da Profa. Dra. Solange Maria da Rocha (2018), catalogados, analisados e registrados em imagens, como se verá ao longo desta seção. Os dois últimos livros de vocabulários ilustrados, acima citados, por exemplo, foram elaborados por professores da instituição visando difundir a língua entre seus docentes, funcionários e alunos. No prefácio do livro Linguagem de Sinais: As mãos também falam, a equipe de elaboração definiu como finalidade do trabalho: "levar aos colegas a linguagem de sinais utilizada pelos deficientes auditivos no Instituto Nacional de Educação de Surdos, considerando-a aquisição fundamental à paciente tarefa de integrar os surdos aos ouvintes" (INES, [1856], $s / p.) .^{5}$

O Linguagem de Sinais: As mãos também falam foi baseado em pesquisas de Maria Bernarda Limeira Mello e elaborado sob orientação de Geraldo Cavalcanti de Albuquerque, junto a uma equipe de professores, alunos, ex-alunos e funcionários surdos do INES. Em seu corpo, foram registradas a ilustração (alguns sinais não possuem ilustração), a palavra em Língua Portuguesa - LP (com fonte em letra cursiva e de imprensa) e, por último, o sinal. A ordenação da nomenclatura não segue a ordem alfabética ou outro critério claro para indexação das palavras ou sinais (ver Figura 4). Nota-se que, em algumas páginas, há a sequenciação semântica, como nos registros para MENINO/MENINA (categoria semântica: seres humanos); CACHORRO/GATO/PATO (categoria semântica: animais), mas esse não é o padrão adotado por toda a macroestrutura, como demonstram as páginas A e B:

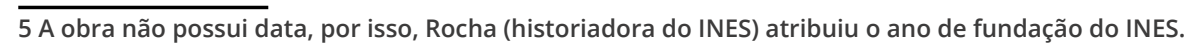


Lexicografia das línguas de sinais: resgate histórico e estudo descritivo Érika Lourrane Leôncio · Claudia Zavaglia

Figura 4 - Páginas alternadas do Manual Linguagem de Sinais [...]

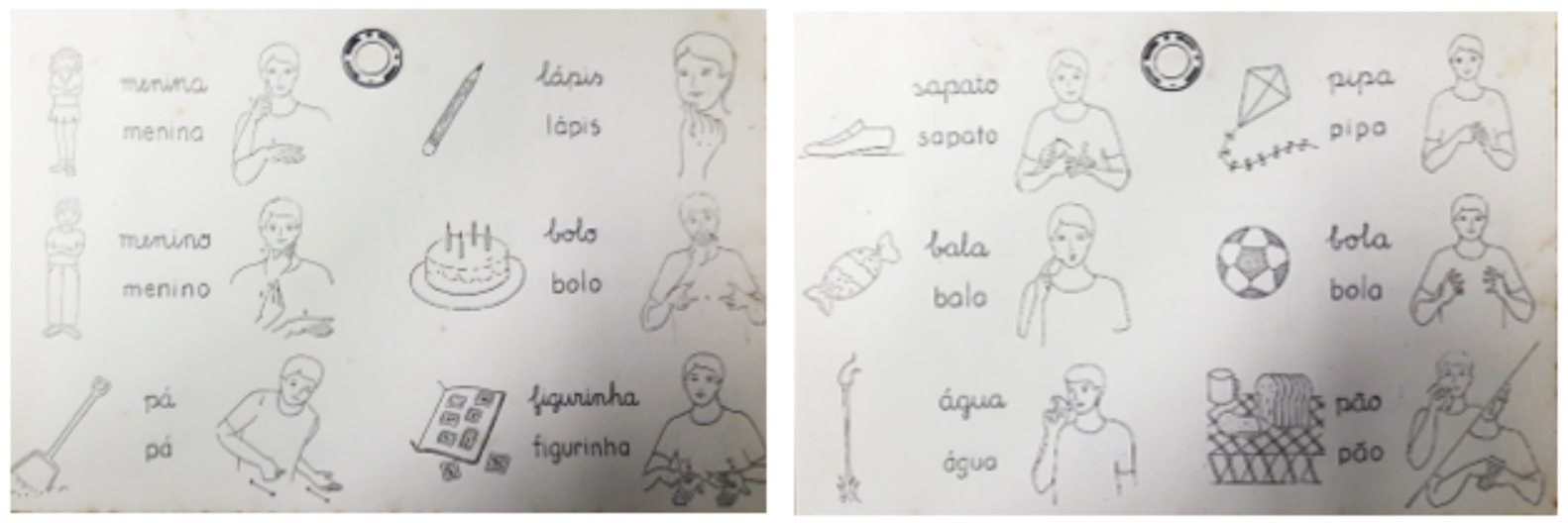

Fonte: Acervo do INES (INES, s.d., s/p.).

Como se observa na página A, o campo semântico para "seres humanos" é interrompido pelo sinal para PÁ (utensílio doméstico ou para construção), que, por sua vez, é seguido por LÁPIS (material escolar) e BOLO (alimento), sendo finalizado com a palavra/ sinal: FIGURINHA, também de campo semântico divergente. O segundo vocabulário, diferentemente, é sistematizado e respeita um padrão para organização da nomenclatura. A obra não possui autoria e data de publicação, foi organizada por campos semânticos e traz o alfabeto manual e os numerais, informações frequentes em obras de LS desta natureza. 
Lexicografia das línguas de sinais: resgate histórico e estudo descritivo Érika Lourrane Leôncio • Claudia Zavaglia

Figura 5 - Página do livro vocabular Comunicando com as Mãos
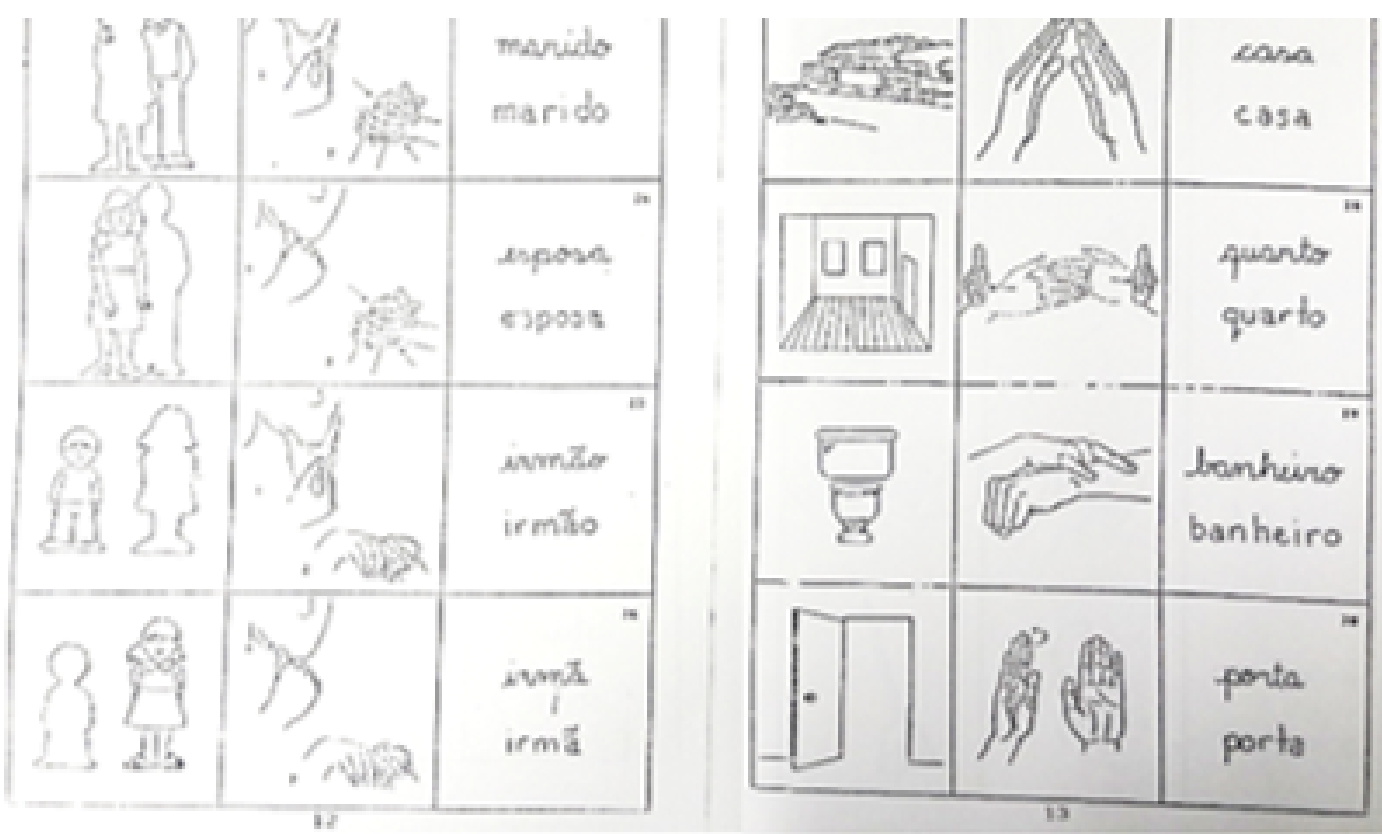

Fonte: Albuquerque ([1856], p. 10-11). ${ }^{6}$

Tanto o Linguagem de Sinais: As mãos também falam como o Comunicando com as Mãos tratam o léxico isoladamente, sem nenhuma informação de forma, semântica ou pragmática, por isso, são considerados como listas vocabulares. A função desse tipo de material é registrar o léxico corrente e auxiliar o aprendizado do sinal, favorecendo a compreensão intralinguística entre os vocábulos da Libras e da LP.

O "dicionário" (como é chamado na apresentação da obra) Linguagem das Mãos, de Eugênio Oates, publicado em 1969, foi a segunda obra de referência para a Lexicografia da Libras. Publicada quase um século após o Iconografia dos Sinais dos Surdos-Mudos, essa obra apresenta metodologias mais condizentes à Lexicografia da época de línguas como o Espanhol. Prova disso é o relato de Burnier (1996 apud Oates, 1969, p. 7) presente na apresentação da referida obra acerca dos procedimentos metodológicos empregados no trabalho, qual seja:

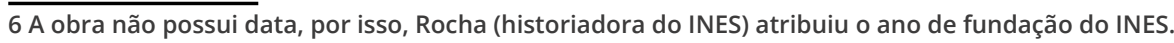


Lexicografia das línguas de sinais: resgate histórico e estudo descritivo Érika Lourrane Leôncio • Claudia Zavaglia

Antes de organizar este dicionário de mímica o nosso amigo, Padre Eugênio, realizou exaustivas pesquisas pelo território nacional, colecionando gestos nos lugares onde conviveu com os surdos. As mímicas escolhidas e colocadas neste manual resultaram do número maior de gestos parecidos. Alguns gestos não existentes no Brasil e presentes neste livro, visaram completar e dar exata expressão do pensamento. Não houve escolha das mímicas com o desejo de agradar mais a um grupo de surdos que a outro. A escolha foi feita cuidadosamente e após acurados os estudos. Houve, também, consultas a surdos e a professores mais conhecedores da linguagem gestual (BURNIER, 1996 apud OATES, 1969, p. 7).

O trabalho de Oates sofreu influência da Lexicografia da Língua de Sinais Americana, doravante ASL (COSTA; NASCIMENTO, 2015), e foi o primeiro a documentar os sinais utilizados em diferentes estados brasileiros e a submeter os sinais à validação de surdos e especialistas conhecedores da língua. Além disso, outra inovação na obra foi a substituição do desenho litográfico pelo registro fotográfico e o uso de setas autoexplicativas para indicar o tipo de movimento e deslocamento(s) da(s) mão(s) (ver Figura 6). Vejamos: 


\section{Figura 6 - Representação do sinal com a descrição verbal}

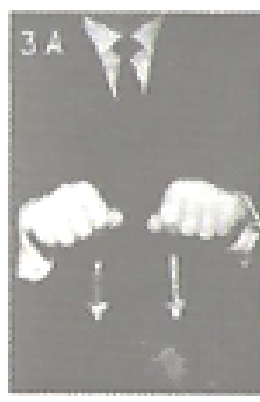

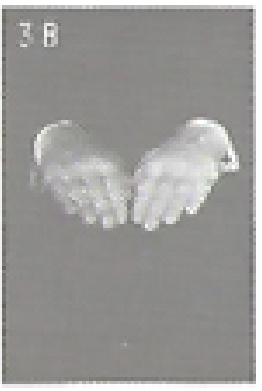

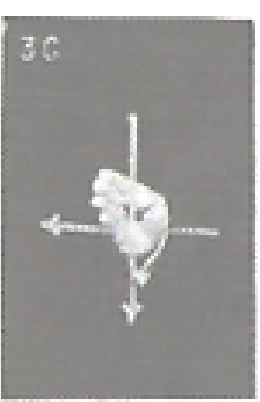

ABENCCOAR - (3) - Mãos fechadas em "A", palmas para baixo. Abrilas lentamente, dando idéia de baixá-las sobre a cabeça de alguém. Logo depois, traçar uma cruz no ar com a măo direita aberta, palma virada para a esquerda, (Benzer, bênçăo).

O Linguagem das Mãos (OATES, 1969) possui 1.258 sinais, 830 unidades lexicais a mais que o Iconografia dos Sinais dos Surdos-Mudos. Ele mantém o sistema de indexação por classe gramatical (verbo e substantivo) e por campo semântico (animais, objetos, cores, alimento, entre outros), adotado também por Gama. Além disso, segue, estritamente, a ordem alfabética, direção onomasiológica, com entradas que são o próprio sinal (considerando a ordem linear de distribuição das informações na microestrutura). Cada sinal foi codificado ao longo da extensão da macroestrutura por número(s) na ordem crescente e com letra(s) do alfabeto da LP. Ao lado do sinal, consta um breve texto que descreve a sua execução. Algumas mudanças fonéticas (configuração de mão, movimento, dentre outros) ou sinais compostos são ilustrados por duas ou mais fotografias codificadas em letras do alfabeto para indicar mudanças de parâmetro ou que o sinal é composto. Por exemplo, se um sinal possui duas sequências lineares com configurações de mão e movimentos distintos, cada imagem é codificada por uma ordem numérica e alfabética correspondente, sucessivamente. 
Lexicografia das línguas de sinais: resgate histórico e estudo descritivo Érika Lourrane Leôncio • Claudia Zavaglia

Por exemplo, o sinal ABENÇOAR ${ }^{7}$ é formado pela aglutinação de dois morfemas livres (benção e cruz); logo, ele inicia e termina com CM's diferentes. Para ilustrar mudanças fonéticas como essa, o autor nomeia as imagens da Figura 8 de 3A e 3B (radical) e $3 C$ (morfema incorporado). Esse sistema simbólico, uma espécie de legenda, adotado por Oates (1960) e outros lexicógrafos ou terminológos, tinha por finalidade explicar a forma de realização do sinal (SOFIATO; REILY, 2012). Krieger (2012) emprega para o termo "legenda" a expressão "chave de leitura". Segundo a autora, a chave de leitura é uma "espécie de código, traduzido por marcas formais" (KRIEGER, 2012, p. 30), utilizadas para orientar a leitura e indicar aspectos semânticos, fonéticos, gramaticais, além de outros. Essas marcas estavam muito presentes na obra de Oates (1960) e influenciaram fortemente o fazer lexicográfico da época, de forma que, até hoje, elas podem ser encontradas em obras. Sobre o sucesso dessa obra, Sofiato (2005) testemunha que:

Sendo considerada uma obra de referência pela sua historicidade e forma de elaboração, muitos autores posteriores se basearam no mesmo tipo de suporte e no uso dos mesmos recursos para criar outras obras semelhantes a essa. Encontramos em várias obras a mesma espécie de enquadramento fotográfico, de escolha lexical e de legendas explicativas apresentadas por Oates em seu livro. Muitos se apropriaram das soluções de Oates, que continuam se perpetuando, apesar das restrições (SOFIATO, 2005, p. 64).

Em virtude da necessidade de difusão da Libras entre as comunidades surdas e instituições de ensino, principalmente, passaram a surgir "iniciativas em termos de estudos linguísticos, materiais de divulgação não especializados e elaboração de dicionários por instituições religiosas, públicas e privadas" (FELIPE, 2001, p. 38). Mesmo com a ausência de recursos de imprensa e vídeo, corpora digital, equipe ampla e diversificada, entre outros, os trabalhos

7 Neste artigo, os exemplos de itens lexicais em Libras estão grafados em caixa alta, conforme convenção (FIGUEIREDO SILVA; SELL, 2009), (FELIPE, 2014) - desde 1988 - dissertação da UFPE. 
Lexicografia das línguas de sinais: resgate histórico e estudo descritivo Érika Lourrane Leôncio • Claudia Zavaglia

lexicográficos na Libras continuaram sendo produzidos no século XIX mais efetivamente como uma técnica e arte do que como uma ciência.

A partir de um breve levantamento histórico em fontes bibliográficas e materiais, com consulta a obras publicadas no INES, desde a sua fundação, compreendendo o período imperial até os dias atuais, foi elaborada uma linha cronológica ${ }^{8} \mathrm{com}$ as principais referências do século XIX ao XXI (ano 2000), a fim de reconstruir o percurso histórico de registro ${ }^{9}$ da Libras e, por conseguinte, a própria história da Lexicografia. Por meio dessa linha sucessória, é possível verificar o período em que a produção de repertórios lexicográficos se organizava, basicamente, como atividade técnica. Vejamos a linha cronológica.

8 Essa cronologia não se finda em si mesma. Ela está aberta a novas referências e pode ser consultada no apêndice I, em versão ampliada.

9 Alguns títulos foram coletados pela pesquisadora no acervo histórico do INES: 1.Linguagem de Sinais do Brasil (Harry Hoemann, Eugênio Oates, ShirleyHoemann); 2. Comunicando com as Mãos (Judy Ensminger); 3. Linguagem de Sinais: as mãos também falam (equipe do INES). 
Lexicografia das línguas de sinais: resgate histórico e estudo descritivo Érika Lourrane Leôncio • Claudia Zavaglia

Figura 7 - Percurso histórico do registro da Libras

PERCUSO HISTÓRICO DO REGISTRO DA LÍNGUA DE SINAIS BRASILEIRA

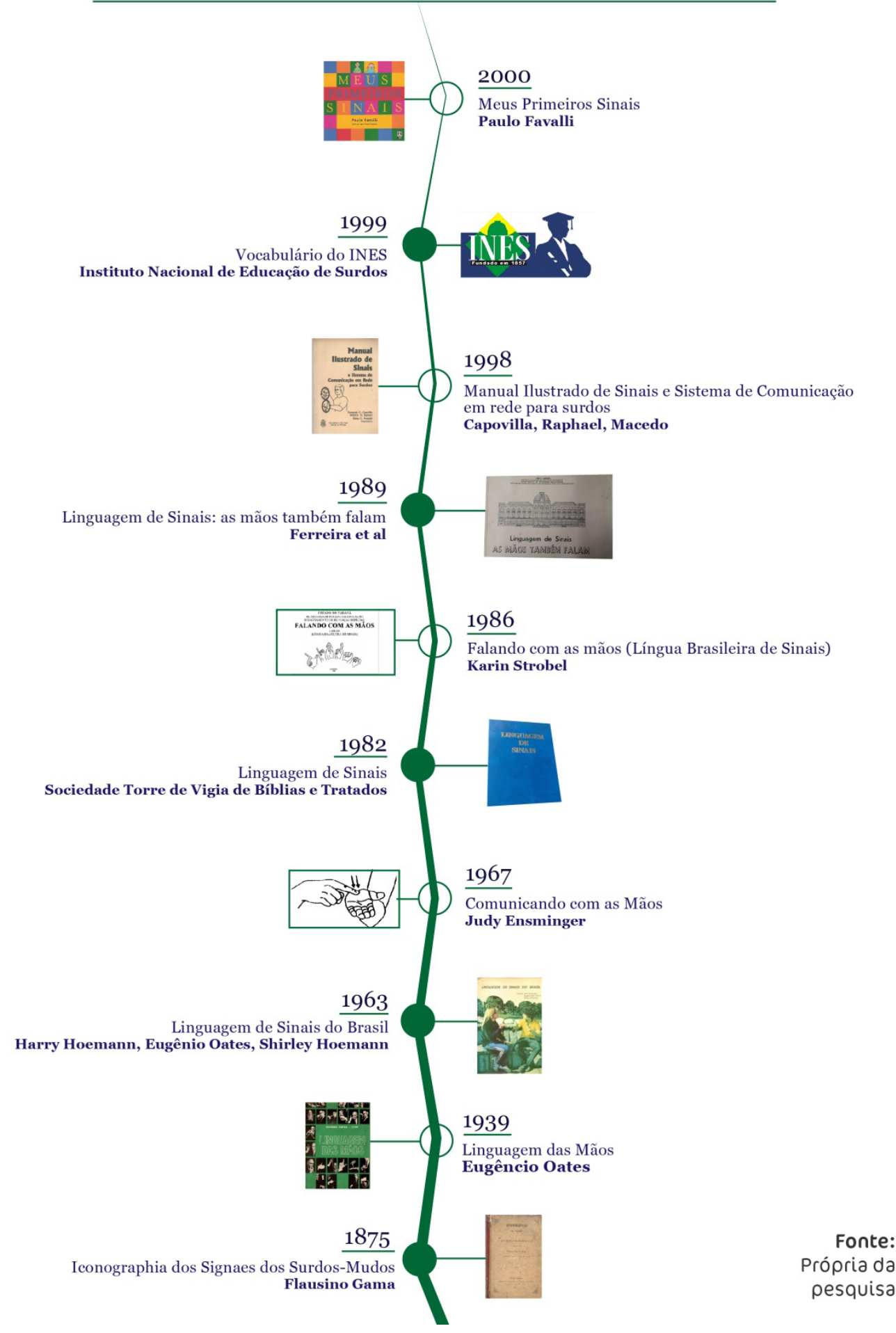

Fonte: Própria da Pesquisa (2018). 
Lexicografia das línguas de sinais: resgate histórico e estudo descritivo Érika Lourrane Leôncio • Claudia Zavaglia

Apenas no início do século XXI, a Lexicografia da Libras começou a se organizar como atividade científica, elaborada por equipe de especialistas e surdos. Os Estudos Linguísticos e Lexicográficos da ASL e da LSF foram as bases teóricas para a Lexicografia da Libras, fato comprovado pelas três primeiras (ordem crescente) obras da linha cronológica da Figura 7.

A ASL foi a língua mais pesquisada no mundo a partir da década de 1970 e sua influência logo foi sentida nos dois primeiros glossários elaborados no Brasil, nas décadas de 1939 e 1963. Assim, Linguagem das Mãos (OATES, 1939/) e Linguagem de Sinais do Brasil (HOEMANN; OATES; HOEMANN, 1963) não só adotaram a metodologia como também acrescentaram sinais da ASL às suas nomenclaturas para suprir os espaços deixados pelos sinais não encontrados nos estados brasileiros.

Apesar das contribuições de obras como essas, autores, como Temóteo (2012), Costa e Nascimento (2015) e Cardoso (2017), destacam que as obras do século XIX e XX, apesar de suas contribuições, aproximaram-se mais a manuais e/ou glossários do que propriamente a dicionários. Além disso, configuravam-se, comumente, mais como obras mistas ${ }^{10}$. Desse modo, para Sofiato e Reily (2014), o primeiro efetivo dicionário de Libras surgiu apenas no século XXI.

Esse dicionário, mencionado pelas autoras, se trata do intitulado Dicionário Enciclopédico Ilustrado Trilíngue: Língua Brasileira de Sinais - LIBRAS (Deit-Libras), publicado em 2001, por Capovilla e Raphael (2001), nas versões impressas e em CD-ROM. Ao todo, tem 3.500 sinais e 9.500 verbetes, em Português.

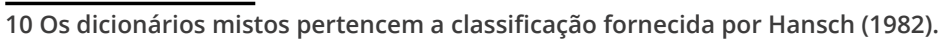


Lexicografia das línguas de sinais: resgate histórico e estudo descritivo Érika Lourrane Leôncio • Claudia Zavaglia

Figura 08 - Capa e verbete do Deit- Libras - Vol. 1 e 2
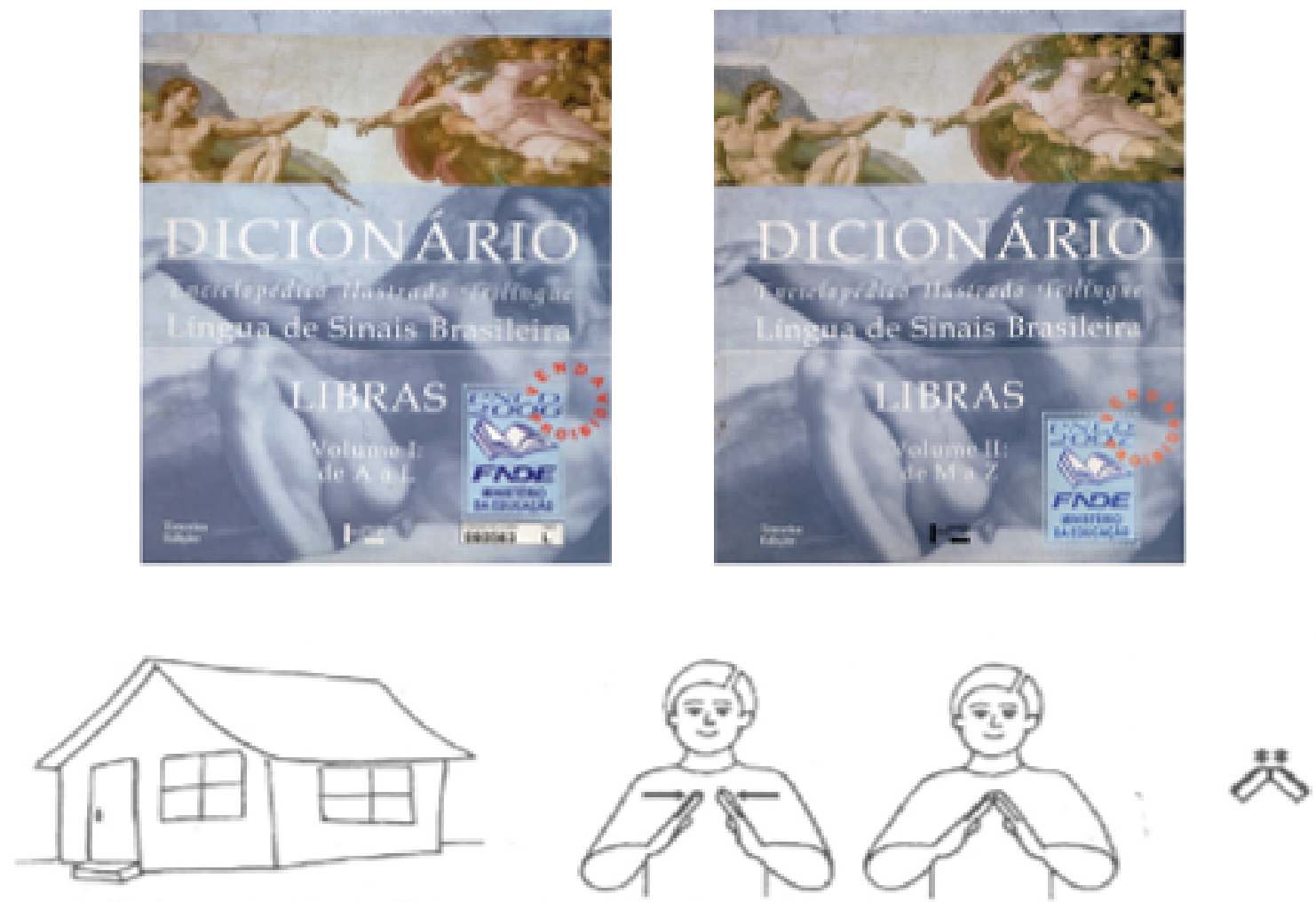

caca (inells: hoste, dwelling, habitation, home, residence, household):

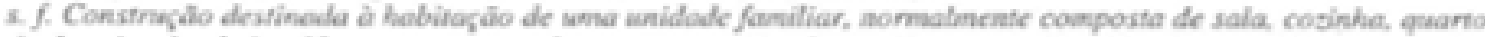

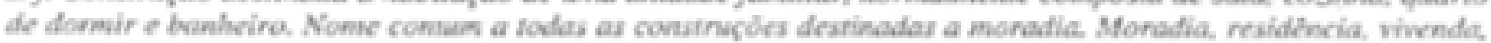
Mabilactlo. Ex.: E. mono na casa dos mras pais.

Mlos verticais abertas, palma a palma, dedos inclinados cns para es cetros. Tocar as mios pelas pontas dos dedos.

Para Sofiato e Reily (2014), a referida obra é uma das mais completas na área da surdez. Ela parece ter sido a primeira a trazer informações de ordem gramatical, semântica e pragmáticas para cada entrada, como convencionalmente fazem os dicionários da ASL, da LSF e da Língua de Sinais Espanhola (LSE), principiantes na atividade prática da Lexicografia da LS.

Conforme Capovilla, Raphael e Maurício (2012), o Deit-Libras (2001) é resultado de pesquisas desenvolvidas desde 1989 no Laboratório de Neuro-Psicolinguística Cognitiva Experimental da Universidade de São Paulo - USP (2012). Ele foi o primeiro de uma 
Lexicografia das línguas de sinais: resgate histórico e estudo descritivo Érika Lourrane Leôncio • Claudia Zavaglia

série de edições ${ }^{11}$ e reimpressões, como a de 2009, que chegou a alcançar três reimpressões em 2011, 2012 e 2015. Além de dicionários, o grupo também publicou o Manual Ilustrado de Sinais de Comunicação em Rede para surdos (CAPOVILLA; RAPHAEL; MACEDO, 1998), a Enciclopédia da Língua de Sinais Brasileira (CAPOVILLA; RAPHAEL, 2004, 2005), Enciclopédia da Língua de Sinais Brasileira: o mundo do surdo em Libras (CAPOVILLA; RAPHAEL, 2004, 2005, 2006, 2011, 2014, 2015, 2016), dentre outros.

\section{Figura 09 - Capa e verbete do Novo Deit- Libras}
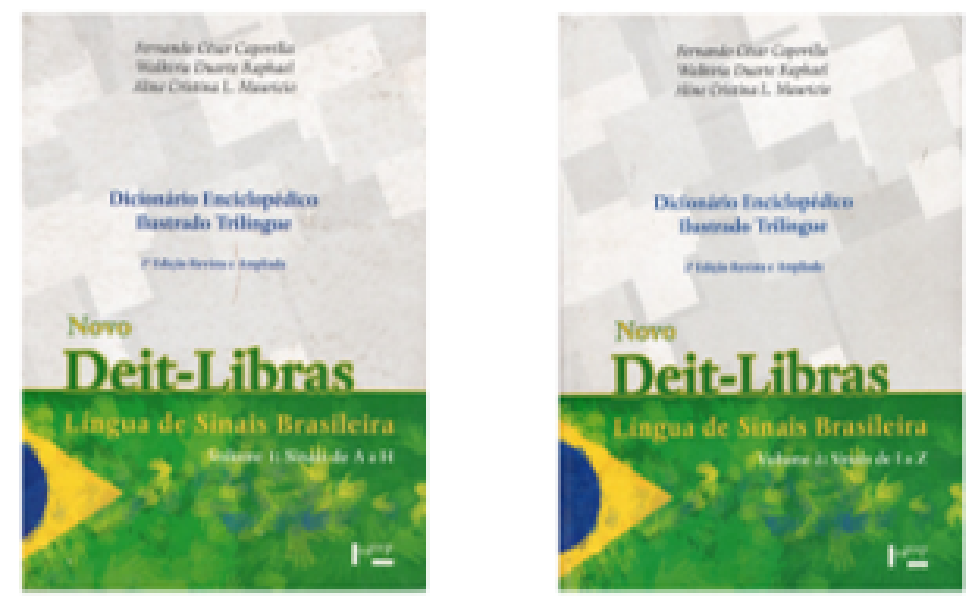

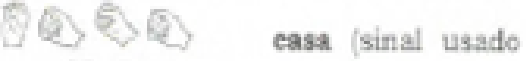
em: $S P, R J$, MS, MG, DF, PR, SC, BA, $P B$, RS) (inglés: house, duelling. habitation, home, resideno, househoid/: s. $f$. Construcdo destincda d̀ habitacio de uma unidade familiar, normatmente cumposta de sala, cozinha, quarto de
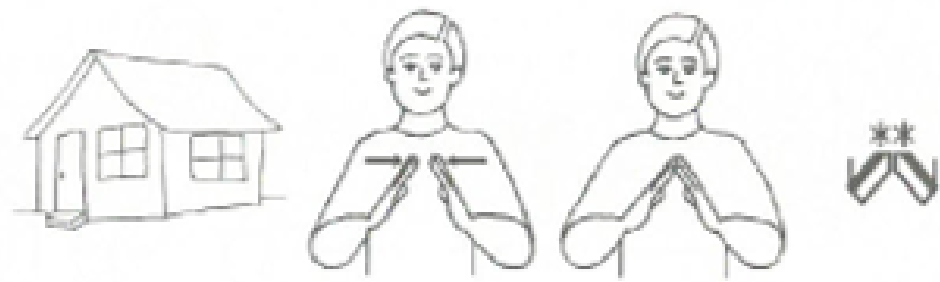

dormir e hanheiro. Nome comum a todas as construpües destinadas a moradia. Moradia, residéncia, sivenda, habitaçlo. Ex: Eu mero na casa dos metus pais. (Maos verticais abertas, palma a palma, dedos inclinados uns para os outros. Tocar as maics pelas pontas dos dedos.]

Fonte: Capovilla, Raphael e Maurício (2012, p.672).

Em 2006, a terceira edição do Deit-Libras foi adotada e distribuída pelo Ministério da Educação e Cultura (MEC) como material didático complementar para as escolas públicas brasileiras (CAPO-

\footnotetext{
11 Primeira edição do Deit- Libras: Dicionário Enciclopédico Ilustrado Trilíngue da Língua de Sinais Brasileira (CAPOVILLA; RAPHAEL, 2001), (CAPOVILLA; RAPHAEL, 2006); Segunda edição do Deit-Libras: Dicionário Enciclopédico Ilustrado Trilíngue da Língua de Sinais Brasileira/ Novo Deit- Libras (CAPOVILLA; RAPHAEL; MAURíCIO, 2009 - 2015) e o Dicionário da Língua de Sinais do Brasil: a Libras em suas mãos (CAPOVILLA et al, 2017).
} 
Lexicografia das línguas de sinais: resgate histórico e estudo descritivo Érika Lourrane Leôncio • Claudia Zavaglia

VILLA; RAPHAEL, 2006, p. 29). O Dicionário da Língua de Sinais do Brasil: a Libras em suas mãos (doravante DLSB), o mais recente lançamento, foi publicado no ano de 2017 por Capovilla, Raphael, Temotéo e Martins (2017). Ele possui três volumes e é, conforme relato dos autores, assim como os demais, o desdobramento de alguns dos dicionários, enciclopédias e manuais anteriores.

Figura 10 - Capa e verbete do DLSB
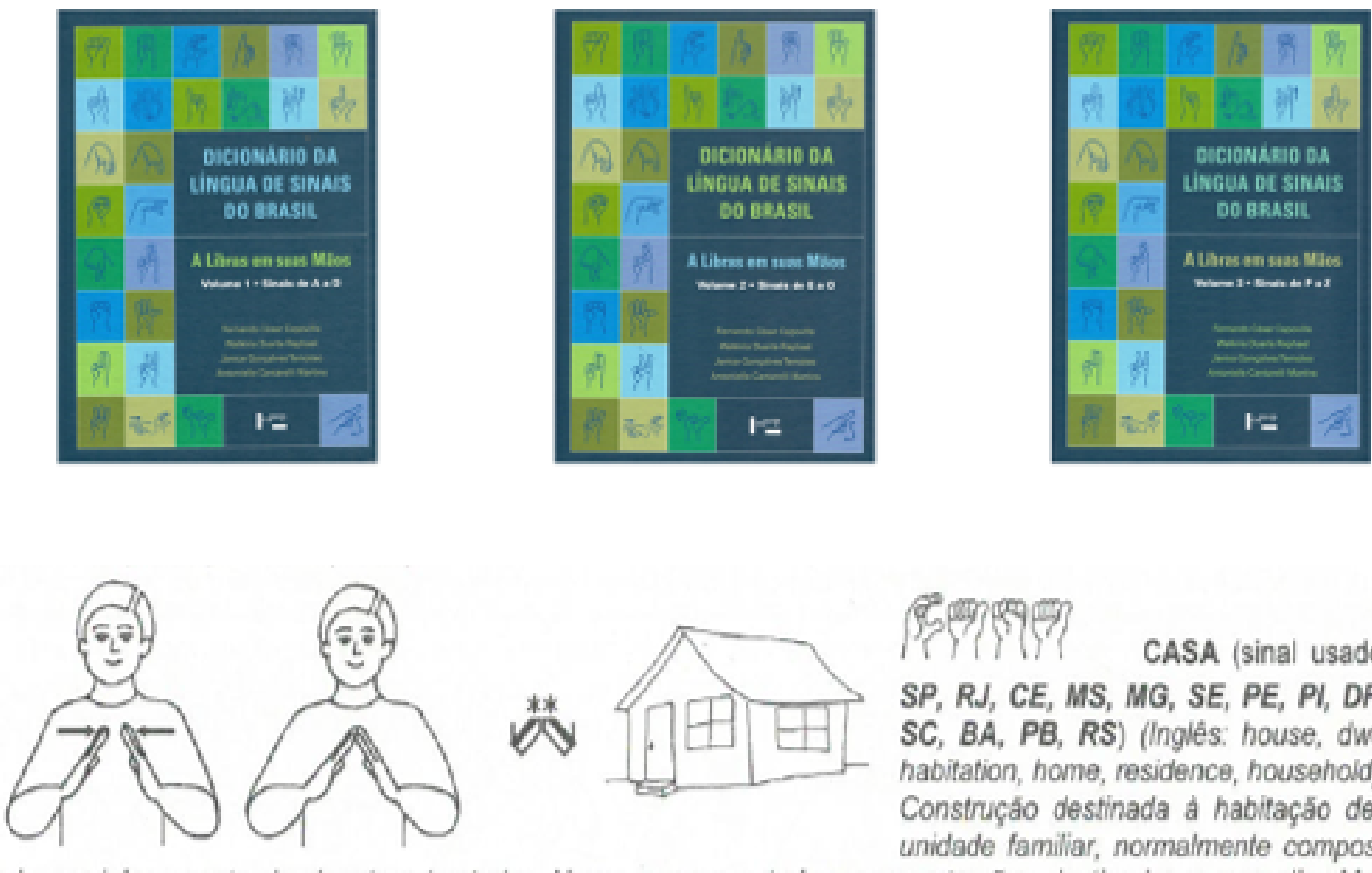

CASA (sinal usado em: $S P, R J, C E, M S, M G, S E, P E, P I, D F, P R$, $S C, B A, P B, R S$ ) (Inglès: house, dwelling. habitation, home, residence, household): s. f. Construçáo destinada à habitaçăo de uma unidade familiar, normalmente composta de sala, cozinha, quarto de dormir e banheiro. Nome comum a todas as construçōes destinadas a moradia. Moradia, residência, vivenda, habitação. Ex: Eu moro na casa dos meus pais. (Mãos verticais abertas, palma a palma, dedos inclinados uns para os outros. Tocar as mãos pelas pontas dos dedos.)

Fonte: Capovilla (et al., 2017, p. 590).

O dicionário acima apresentado foi o primeiro a não receber o título de Enciclopédico, e isso parece justificar a retirada de grande parte dos textos introdutórios ${ }^{12}$ constantes nos dicionários anteriores. Na edição de 2012 havia 217 páginas só de textos introdutórios; e na de 2017 apenas 25 páginas (ilustração do alfabeto, números e formato de mão e as orientações para uso), antece-

120 uso do termo "textos introdutórios" está sendo empregado conforme a classificação de Haensch (1982) para dicionário, a saber: 1. Parte introdutória; 2. Corpo do dicionário; 3. Anexos. 
Lexicografia das línguas de sinais: resgate histórico e estudo descritivo Érika Lourrane Leôncio • Claudia Zavaglia

dendo a macroestrutura. Uma estranha decisão, jamais vista nas versões anteriores, foi a omissão da quantidade de sinais, palavras em português e em inglês que compõem seu vocabulário. Nas demais edições, logo nas primeiras páginas introdutórias, os autores documentavam a quantidade de sinais, incluindo textos como: "3.1. Os 9.021 verbetes em Português que correspondem aos 10.296 sinais de Libras; 3.2 ) Os 13.757 verbetes em Inglês que correspondem aos 9.021 verbetes em Português; [...]" (CAPOVILLA et al., 2012, p. 45).

A extensão da macroestrutura de um dicionário é uma informação importante tanto para o consumidor quanto para o pesquisador. Para o consumidor, porque o ajuda a orientar a sua compra; e, para o pesquisador, porque o tamanho da nomenclatura the fornece pistas sobre a classificação tipológica do produto (BIDERMAN, 1994). Apesar de não haver dados sobre o tamanho da nomenclatura das três línguas, notamos que o dicionário expandiu a cobertura da variação diatópica a todos os estados brasileiros, registro até então nunca visto em qualquer outra produção dessa natureza no país ${ }^{13}$, o que é um ganho irrefutável para a comunidade em questão.

Além da rede de dicionários de Capovilla, existe, também, o Dicionário llustrado de Libras (a partir de agora, DIL), de autoria de Flávia Brandão, publicado em 2011 e reimpresso em 2016. Sua macroestrutura é composta por 3.212 sinais e 7.800 palavras em português. Vejamos a capa e o verbete do sinal CASA:

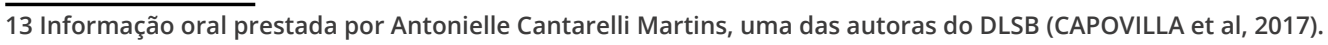


Lexicografia das línguas de sinais: resgate histórico e estudo descritivo Érika Lourrane Leôncio • Claudia Zavaglia

Figura 11 - Capa e verbete do Dicionário llustrado de Libras - Vol. Único
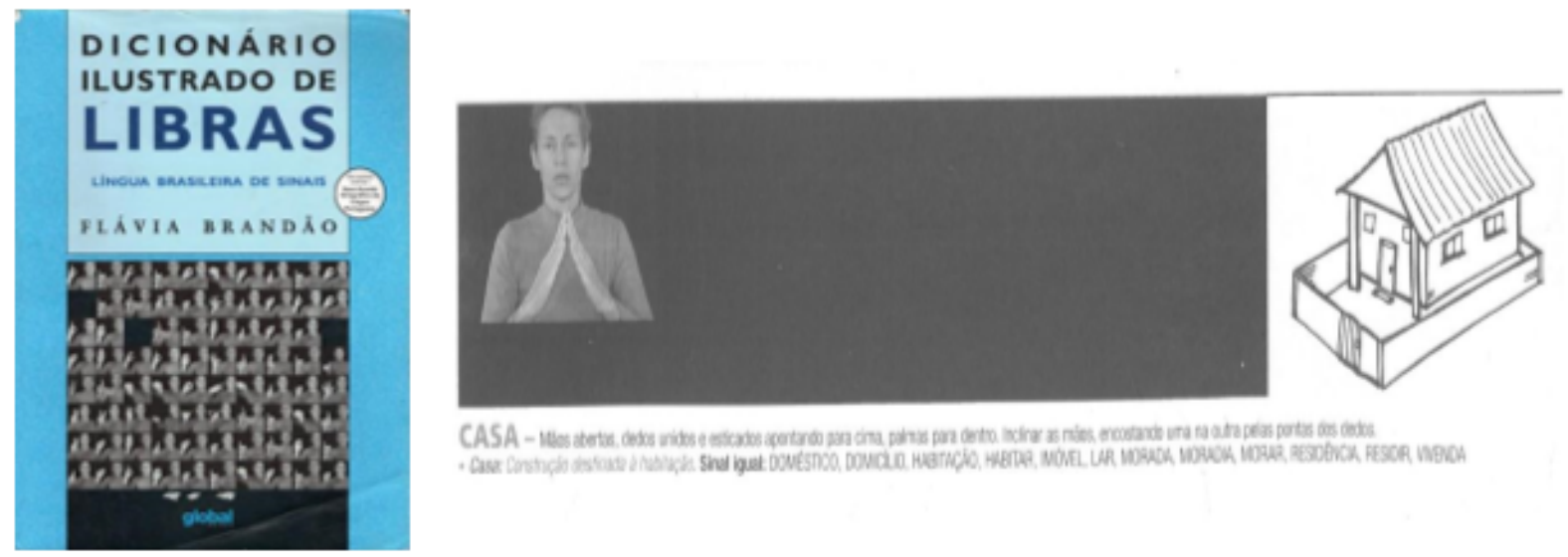

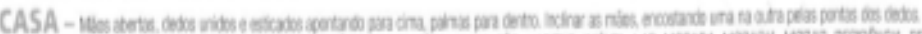

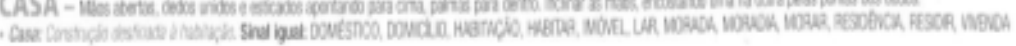

Fonte: Brandão (2011, p.160).

De todas as obras de natureza lexicográficas analisadas e comparadas nesta pesquisa, apenas o Deit-Libras, o DLSB e o DIL podem ser considerados como efetivos dicionários, pelo conteúdo e tipo de informações trazidas nos verbetes.

A coleção unificada Libras: a imagem do pensamento, de Kojima e Segala (2012), foi citada por Cardoso (2017) como um dicionário em suporte impresso, dividido em oito capítulos e com uma lista vocabular (terceiro capítulo) de verbetes separados por CM.

Apesar da tentativa de Cardoso (2017) de legitimar a obra como um dicionário, pelas características do trabalho, ele não chega à envergadura de um dicionário. Suas características estão mais próximas a um manual instrucional ou vocabulário: "lista de palavras dispostas em ordem alfabética, com ou sem definição" (ZAVAGLIA, 2012, p. 238). No recorte abaixo, é possível verificar que, no enunciado lexicográfico dos verbetes, não há nenhuma espécie de definição ou informação gramatical além da descrição fonológica do sinal e sua ilustração. 
Lexicografia das línguas de sinais: resgate histórico e estudo descritivo Érika Lourrane Leôncio • Claudia Zavaglia

Figura 12 - Sistema de organização do vocabulário

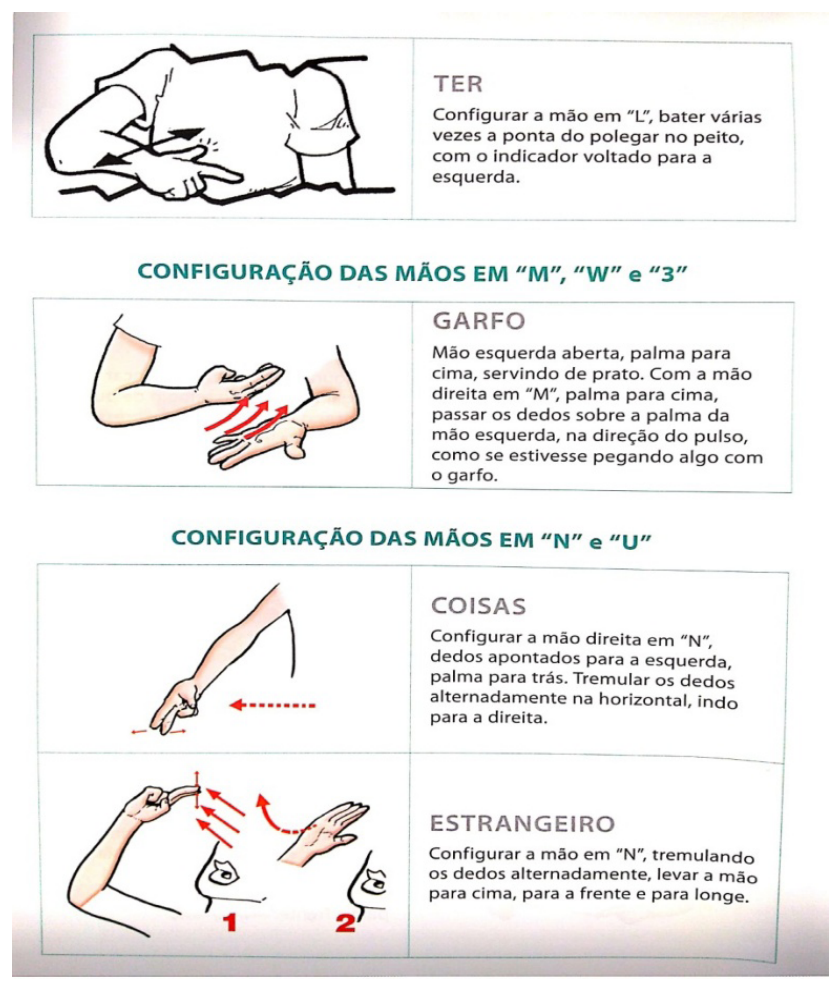

Fonte: Kojima e Segala (2012, p. 60).

Apesar de pouco conhecida, essa produção utilizou o sistema de indexação por Configuração de Mão, já bastante avançado, inclusive para os primeiros dicionários gerais de LS que surgiam na época da primeira impressão do trabalho de Kojima e Segala, em 2001.

Mesmo ainda com o limitado número de dicionários impressos, a Libras dispõe não somente dessas obras e de glossários e vocabulários impressos, mas também de repertórios lexicográficos e terminológicos digitais que, ao longo do século, foram ganhando espaço e se multiplicando rapidamente no país. Para citar algumas de suporte digital, organizamos o quadro a seguir: 
Lexicografia das línguas de sinais: resgate histórico e estudo descritivo Érika Lourrane Leôncio • Claudia Zavaglia

\section{Quadro 02 - Obras lexicográficas e terminológicas digitais}

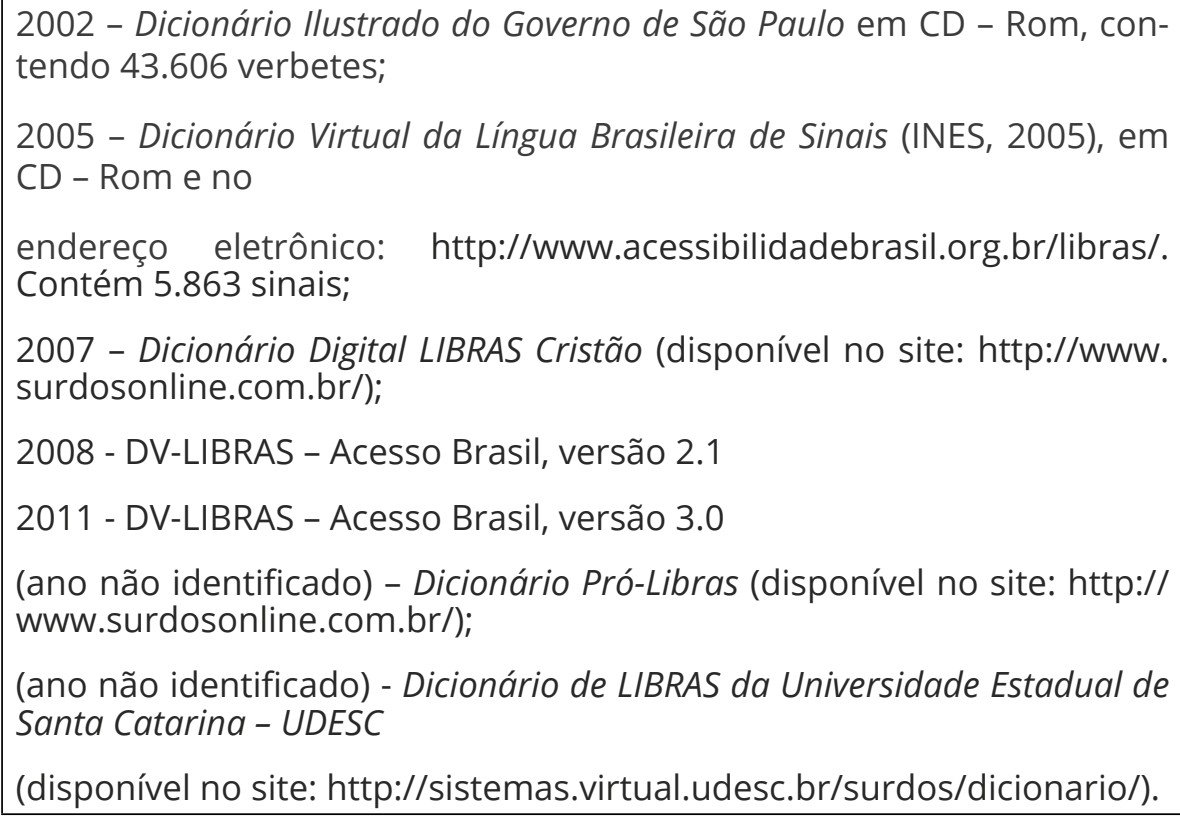

Fonte: Própria da Pesquisa (2020).

Destes dicionários digitais, o Dicionário Virtual da Língua Brasileira de Sinais - LIBRAS (DV-Libras), elaborado pela equipe técnica do INES e FENEIS em parceria com o Governo Federal, nas versões 1.0 (ano 2001) e 2.0 (ano 2005), online e em CD-Rom, recolheu mais de 5 mil sinais e registrou mais de 3.986 verbetes na sua segunda versão, sendo pioneiro na história da Lexicografia de Dicionários Digitais da Libras. Ele registra a unidade lexical em vídeo-gravações, oferecendo "a possibilidade de acompanhar o sinal sendo realizado a partir de todos os parâmetros que o compõem" (FELIPE, 2001, p. 41).

O DV-Libras inovou em diferentes aspectos, haja vista que, na própria página do dicionário, é possível verificar todos os recursos e inovações do produto, proporcionados pelos avanços tecnológicos computacionais da época. O campo F: "Exemplo Libras" é uma das diferenças entre ele e os demais glossários e dicionários. Ele fornece a transcrição do exemplo de uso do Português para a Li- 
Lexicografia das línguas de sinais: resgate histórico e estudo descritivo Érika Lourrane Leôncio • Claudia Zavaglia

bras através do sistema de glosas ${ }^{14}$ elaborado por Felipe (1988; 1998) e denominado: Sistema de Transcrição em Palavra.

Figura 13 - Verbete virtual do DV-Libras

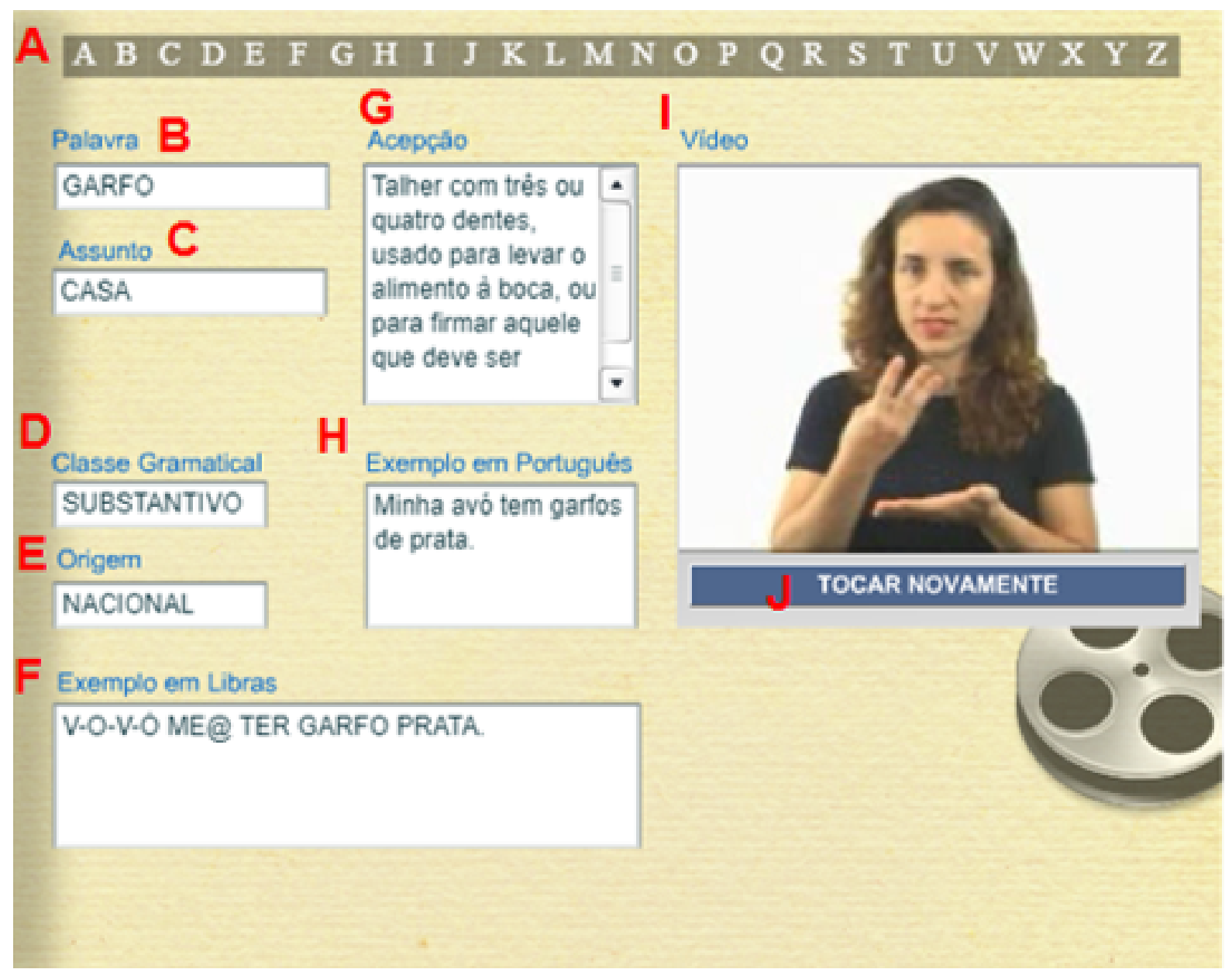
A - campo de busca por ordem alfabética
F - exemplo com transcrição em Libras
B - busca pela palavra
G - definição
C - assunto ou campo semântico
H - exemplo em Português
D - classificação gramatical
I - vídeo com a execução do sinal
E - variação diatópica
J - repetição do vídeo

Fonte: INES (FELIPE; LIRA, 2005).

14 Conforme Felipe (2014), "glosas" é um sistema de representação semântico-discursiva do sinal. Trata-se de uma convenção para representar os sinais da Libras por meio de palavras, sinais gráficos e tipográficos. 
Além dos dicionários gerais (impressos ou digitais), muitas obras terminológicas também foram desenvolvidas no país, tais como: o Dicionário Digital Libras Cristão (2007), o Dicionário de Informática em Libras da FENEIS (Federação Nacional de Educação e Integração de Surdos) (2015), o Varlibras, desenvolvido por Castro (2014), dentre inúmeros outros.

É importante haver clareza sobre as diferenças entre dicionários gerais ou especiais e obras terminológicas. Para diferenciar tais gêneros, Krieger (2006, p. 143) define dicionários técnico-científicos ou terminológicos como aqueles que arrolam os termos técnico-científicos de alguma área do conhecimento e que, "muito comumente, aparecem sob a forma de glossários, restringem-se a repertoriar o que é convencionalmente chamado de léxico especializado".

Um exemplo desse tipo de obra é o dicionário de Libras do Núcleo de Estudos e Pesquisa em Educação de Surdo (NEPES/SC), intitulado Dicionário de Ciências (s/d), que lematiza apenas os sinais das áreas de educação, ciência e tecnologia (Geografia, História e Ciências), do Instituto Federal de Santa Catarina, Campus São José.

Diferentemente, Krieger (2006) pontua que o dicionário geral busca cobrir a totalidade do léxico de uma língua com base no critério de frequência de uso, além de assumir caráter semasiológico. Já os técnico-científicos, segundo a autora, partem do conceito para a unidade lexical específica, por isso, podem ser considerados onomasiológicos. Para Krieger (2006), a diferença fundamental entre dicionário e glossário são as informações gramaticais e semânticas inseridas no primeiro e ausentes no segundo. Ambos selecionam a nomenclatura a partir dos tipos ou objetivos para os quais a obra irá servir. A nomenclatura, que nada mais é do que o conjunto de unidades lexicais, é definida a partir dos objetivos que o lexicógrafo deseja alcançar.

Apesar da proliferação e da facilidade de acesso a glossários digitais, os dicionários impressos da Libras, mesmo em número menor, renovam-se ou passam por reformulações em períodos 
Lexicografia das línguas de sinais: resgate histórico e estudo descritivo Érika Lourrane Leôncio • Claudia Zavaglia

menores. A rede de dicionários de Capovilla, por exemplo, renova-se, em média, a cada um ou dois anos, aumentando o vocabulário, tipos de informações e ampliando a representação diatópica da língua.

Sofiato e Reily (2014) acreditam que os últimos títulos e edições de obras lexicográficas da primeira década deste século revelam que os dicionários impressos ainda são muito consultados, principalmente como material de apoio e suporte à memória lexical nas aulas da disciplina de Libras. Surdos e ouvintes procuram esses dicionários tanto para aprender um sinal novo quanto para tirar dúvidas relacionadas à definição fonológica e outras, de ordem semântica e/ou pragmáticas.

\section{Conclusão}

Neste artigo, foi desenvolvido um estudo metalixicográfico sobre as principais produções lexicográficas da LS no mundo e no Brasil (principalmente) e o continuum de produções e escolhas lexicográficas empregadas na macro e microestrutura de algumas das tipologias encontradas no corpora da pesquisa (manuais vocabular, listas de vocabulários e dicionários de Libras).

Por meio da pesquisa metalexicográfica, identificamos que, até o momento, os primeiros registros lexicográficos e, também, terminológicos das LS surgiram no contexto religioso da vida monástica, na Idade Média, em locais isolados da Europa e América do Norte. Ambas as regiões tiveram forte influência sobre o registro dos sinais e a Lexicografia brasileira. A exemplo, o Iconographia dos Signaes dos Surdos-Mudos (GAMA, 1875), primeiro registro lexicográfico, fortemente influenciado pela Lexicografia europeia (iniciada décadas antes, na Alemanha), e o Dicionário Linguagem das Mãos, de Eugênio Oates (1969), baseado na metodologia lexicográfica da ASL e línguas como o Espanhol falado.

Dentre o acervo levantado, verificamos que as listas e manuais vocabulares foram as primeiras tipologias a registrar os sinais. 
Lexicografia das línguas de sinais: resgate histórico e estudo descritivo Érika Lourrane Leôncio • Claudia Zavaglia

Abrindo espaço, posteriormente, para novas tipologias e outros tipos de informações, para além da lexia e sua instrução fonológica de uso. Algo frequentemente observado ao longo das análises teórico-linguísticas foi a hibridez entre as obras lexicográficas que, geralmente, apresentavam características distintas para mais de uma tipologia. Além disso, também verificamos que uma mesma denominação era aplicada, por autores e editores, de forma arbitrária para obras distintas. Das 12 obras estudadas, apenas seis se tratavam, efetivamente, de dicionários (ver Quadro 1), refletindo um corolário proveniente da Lexicografia das línguas faladas, a exemplo da língua espanhola e portuguesa.

A descrição dos diferentes tipos de obras lexicográficas de uma língua é uma tarefa árdua, pois envolve, segundo Haensch (1982 apud PARREIRA DA SILVA, 2007, p. 284), etapas distintas de pesquisa como o levantamento histórico dos trabalhos existentes e a análise teórico-linguística das obras. Nesta pesquisa, foram aplicadas tais etapas, porém, em virtude da riqueza e dimensão das obras exploradas, as análises, estudos e discussões não se encerram aqui, uma vez que pesquisas desta natureza e amplitude requerem acuidade, tempo e mais espaços para discussão.

\section{Referências}

ALBUQUERQUE, G. C. (Org.). Comunicando com as Mãos, Rio de Janeiro: INES, 1856.

BIDERMAN, M. T. C. A nomenclatura de um dicionário de língua.

Estudos linguísticos, São Paulo, v. 1., p. 26-42, 1994.

BRANDÃO, F. Dicionário Ilustrado de Libras. São Paulo: Editora Global, 2011.

CAPOVILLA, F. C.; RAPHAEL, W. D. Dicionário Enciclopédico Ilustrado

Trilíngue: Língua de Sinais Brasileira. São Paulo: Edusp, v. 1, 1. ed., 2001. 
Lexicografia das línguas de sinais: resgate histórico e estudo descritivo Érika Lourrane Leôncio · Claudia Zavaglia

CAPOVILLA, F. C. et al. A. C. Novo Deit-Libras: Dicionário enciclopédico ilustrado trilíngue da Língua de Sinais Brasileira (Libras). São Paulo: Edusp, v.1, 2. ed., 2012.

CAPOVILLA, F. C.; RAPHAEL. Dicionário Enciclopédico Ilustrado Trilíngue: Língua de Sinais Brasileira. São Paulo: Edusp, MEC-FNDE, v.1, 3.ed., 2006.

CAPOVILLA, F. C.; RAPHAEL. Dicionário Enciclopédico Ilustrado

Trilíngue: Língua de Sinais Brasileira. São Paulo: Edusp, MEC-FNDE, v.2, 3.ed., 2006b.

CAPOVILLA, F. C. et al. Dicionário da Língua de Sinais do Brasil: a Libras em suas mãos. São Paulo: EDUSP, 2017.

CARDOSO, V. R. Os dicionários da língua brasileira de sinais e suas contribuições. Revista Sinalizar, Goiânia, v. 2, n.1, p. 50 - 66, jan./jun., 2017.

CASTRO JÚNIOR, Gláucio de. Projeto varlibras. 2014. 259 f. Tese (Doutorado em Linguística) - Universidade de Brasília, Brasília, 2014. COSTA, E. da S.; NASCIMENTO, L. R. S. Os dicionários virtuais e impressos da língua brasileira de sinais. Anais. Encontro Internacional de Formação de Professores e Fórum Permanente de Inovação Educacional. Sergipe, v.8, n.1, 2015.

ERIKSSON, P. Dövas Historias: daubhar - daufr - dörver - döv. Sih Läromedel, 1993.

FELIPE, T. A. Projeto Dicionário Virtual da Libras. Rio de Janeiro:

Fórum 4 - Instituto Nacional de Educação de Surdos, v. 1, jul./dez., 2001. Disponível em: <https://drive.google.com/file/d/OBwAEnJAISYTTZEFSR2F3VGd0cWs/view> Acesso em: 03. jan. 2018.

FELIPE, T. A. Introdução à gramática da Libras. In: BRASIL, FERREIRABRITO, Lucinda (Org.). Educação Especial Língua Brasileira de Sinais. Brasília: SEESP, v. 3, 1997.

FELIPE, T. A. Banco de dados e sistemas de transcrição para as línguas de sinais. In: BAALBAKI, A. C. B. (Org). Instrumentos linguísticos: usos e atualizações. Araruama: Cartolina Editora, 2014. 
FELIPE, T. A. Os processos de formação de palavra na Libras. Campinas: ETD - Educação Temática Digital, v.7, n. 2, jun. 2006. Disponível em: https://periodicos.sbu.unicamp.br/ojs/index.php/etd/ article/view/803 Acesso em: 03. jan. 2018.

FELIPE, T. A. De flausino ao grupo de pesquisadas da FENEIS-PJ. In: Anais do Seminário Surdez: desafios para o próximo milênio. Rio de Janeiro: INES, 2000. Disponível em: https://drive.google.com/drive/folders/0B6WyKJSZvdJdNmFpQ1IWb001TEk Acesso em: 03. jan. 2018.

FELIPE, T. A. Libras em contexto: Curso Básico/Livro do Estudante. 7 ed. MEC-SEESP-FNDE. Brasília, 2007. Disponível em: https://librasgerais. com.br/materiais-inclusivos/downloads/libras-contexto-estudante.pdf http://www.faseh.edu.br/biblioteca_/arquivos/acervo_digital/Libras_ em_contexto_Livro_do_Professor.pdf Acesso em: 03. jan. 2018.

FELIPE, T. A. O signo gestual-visual e a sua estrutura frasal na língua de sinais dos centros urbanos brasileiros. 1988. 105f. Dissertação (Mestrado em Linguística) - Centro de Artes e Comunicação, Universidade Federal de Pernambuco, Recife, 1988.

FELIPE, T. A. A relação sintático-semântica dos verbos na língua brasileira de sinais (LIBRAS). 1998. 143f. tese (Doutorado em Linguística) - Centro de Letras e Artes, Universidade Federal do Rio de Janeiro, Rio de Janeiro, 1998.

FELIPE, T. A. Pela Regulamentação da Lei 10.436, 24 de abril de 2002. Ano V, n. 24, p. 13-14, janeiro/março, 2005.

FELIPE, T. A. O INES e a educação de surdos no Brasil. Rio de Jeneiro:

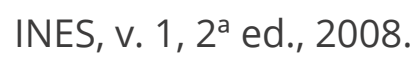

FELIPE, T. A.; LIRA, G. A. Dicionário Virtual de Língua Brasileira de Sinais. cd-rom/online. Versão 2.0. Rio de Janeiro: INES, 2005. Disponível em:<http://www.ines.gov.br/dicionario-de-libras/main_site/libras.htm>Acesso em: 03. jan. 2018.

GAMA, J. da F. Iconoghaphia dos signaes dos surdos-mudos. Rio de Janeiro: Typographia Universal de E \& H Laemmert, 1875.

GAMA, J. da F. Iconoghaphia dos signaes dos surdos-mudos. Série Histórica do INES. Rio de Janeiro: INES, 2011 [1875]. 
Lexicografia das línguas de sinais: resgate histórico e estudo descritivo Érika Lourrane Leôncio • Claudia Zavaglia

HAENSCH, G.et al. La lexicografía. Madrid: Editorial Gredos, 1982. HOEMANN, W. H.; OATES, E.; HOEMANN, S. Linguagem de Sinais do Brasil. Porto Alegre: Centro educacional para deficientes auditivos, 1983.

INES. Linguagem de Sinais: as mãos também falam. Rio de Janeiro: MEC/SEESP, [1856].

INES. O INES e a educação de surdos no Brasil. v. 1, $2^{\text {a }}$ ed. Rio de Janeiro: INES, 2008. PARREIRA DA SILVA, M. C. Para uma tipologia geral de obras lexicográficas. In: ISQUERDO, A. N., ALVES, I. M. (Orgs.). As ciências do léxico: Lexicologia, Lexicografia, Terminologia. v. 3. Campo Grande: Ed. UFMS; São Paulo: Humanitas, p. 283-293, 2007.

KOJIMA, C. K.; SEGALA, S. R. A imagem do pensamento: Libras. São Paulo: Escala educacional, 2012.

KRIEGER, Maria da Graça. Dicionário em sala de aula: guia de estudos e exercícios. Rio de Janeiro: Lexikon, 2012.

KRIEGER, Maria da Graça. Tipologias de dicionários: registros de léxico, princípios e tecnologias. Calidoscópio, São Leopoldo, vol. 4, n. 3 , p. 141-147, set/dez 2006.

LIRA,G. A. Dicionário digital da Língua Brasileira de Sinais - concepção e desenvolvimento do projeto. In: ANAIS DO INES, Rio de Janeiro: Gráfica do INES, 2001.

MOURA, M. C. O Surdo: caminhos para uma nova identidade. Rio de Janeiro: Editora Revinter, 2000.

OATES, E. Linguagem das mãos. Rio de Janeiro: Gráfica editora livro S.A, 1969.

PARREIRA DA SILVA, M. C. Para uma tipologia geral de obras lexicográficas. In: ISQUERDO, A. N., ALVES, I. M. (Orgs.) As ciências do léxico: Lexicologia, Lexicografia, Terminologia. v. 3. Campo Grande: Ed. UFMS; São Paulo: Humanitas, p. 283-293, 2007.

PÉLISSIER. Iconographie des signes, avec des notes explicatives. Paris: Imprimerie et Librarie de Paul Dupont, 1856. 
SCHLÜNZEN, E. TOMOE M.; DI BENEDETTO, L. dos S.; SANTOS, D. A. do N. dos. História das pessoas surdas: da exclusão à política educacional brasileira atual. São Paulo: Unesp/UNIVESP, v. 11, 2013.

SOFIATO, C.; REILY, L. Dicionários e manuais de língua de sinais: análise crítica das imagens. In: SOFIATO; Cássia, et al. Língua Brasileira de Sinais - Libras: aspectos linguísticos e históricos. São Carlos: UABUFSCar/EdUFSCar, 2012.

SOFIATO, C.; REILY, L. Dicionarização da língua brasileira de sinais: estudo comparativo iconográfico e lexical. São Paulo: Educação e Pesquisa, v. 40, n.1, 2014.

SOFIATO, C. O desafio da representação pictórica da Língua de Sinais Brasileira. 2005. 124 f. Dissertação (Mestrado do Curso de Artes Visuais) - Instituto de Artes, Universidade Estadual de Campinas UNICAMP, SP, 2005.

SOFIATO, C. Do desenho à litografia: a origem da língua brasileira de sinais. 2011. 265 f. Tese (Doutorado do Curso de Artes Visuais) Instituto de Artes, Universidade Estadual de Campinas - UNICAMP, SP, 2011.

STOKOE, W. Sign and Culture: A Reader for Students of American

Sign Language. Listok Press, Silver Spring, MD. 1960.

TEMÓTEO, Janice Gonçalves. Lexicografia da Língua de Sinais

Brasileira do Nordeste. 2012. 252 f. Tese (Doutorado em Psicologia Experimental) - Universidade de São Paulo - USP, São Paulo, 2012.

ZAVAGLIA, C. Metodologia em ciências da linguagem: lexicografia. In: GONÇALVES, Adair Vieira; GÓIS, Marcos Lúcio de Sousa (Orgs.). Ciências da linguagem: o fazer científico. 1. ed. 1.v. Campinas: Mercado de Letras, 2012. 